\title{
Analysis of thermosyphon/heat pipe integration for feasibility of dry cooling for thermoelectric power generation
}

Steven P. Benn ${ }^{\mathrm{a}}$, Leonard M. Poplaski ${ }^{\mathrm{a}}$, Amir Faghri, ${ }^{\mathrm{a}, *}$, Theodore L. Bergman ${ }^{\mathrm{b}}$

${ }^{a}$ Department of Mechanical Engineering, University of Connecticut, 191 Auditorium Road, Storrs, CT 06269-3139, USA

${ }^{\mathrm{b}}$ Department of Mechanical Engineering, The University of Kansas, 1530 W. 15th St, Lawrence, KS 66045, USA

* Corresponding author. Tel.: +1 8604860419.

E-mail address: faghri@engr.uconn.edu (A. Faghri). 


\begin{abstract}
Areas of minimal freshwater often struggle to provide the large amounts of water required for industrial processes, such as for the cooling of thermoelectric power plants. In an effort to decrease the water losses of a typical $500 \mathrm{MW}_{\mathrm{e}}$ thermoelectric plant, two concepts are investigated: i) replacing the existing steam condenser with a direct-dry condenser, to provide the phase change and heat rejection of previous once-through and re-circulation cooling systems, and ii) replacing the conventional wet cooling towers with completely dry indirect cooling of the recirculation water stream. For each concept, innovative hybridization of existing systems with closed two-phase thermosyphons allows for the necessary heat transfer of the power cycle. A modular top-down approach to system design allows for manufacturing and installation simplification, and system performance is considered in terms of thermal and cost analysis. The proposed direct steam condenser with heat rejection to ambient air yields an effectiveness, coefficient of performance, and cost per $\mathrm{kW}_{\text {th }}$ of $0.55,376$, and $\$ 31 / \mathrm{kW}$ th, while the dry indirect cooling tower performance specifications are $0.77,206$, and a cost per $\mathrm{kW}_{\text {th }}$ of $\$ 54 / \mathrm{kW}_{\text {th }}$, respectively. These values are near-to or exceed federally proposed standards for dry cooling of thermoelectric plants and outperform existing dry-cooling systems, proving the feasibility of each heat rejection design. Hybrid arrangements of the dry condenser and dry cooling towers are also presented and analyzed, which provide easier retrofit, along with lower costs and greater water savings if combined with existing conventional wet cooling components.
\end{abstract}




\section{Nomenclature}

$\begin{array}{lll}A & \text { area }\left[\mathrm{m}^{2}\right] \\ A_{c} & \begin{array}{l}\text { free flow area of heat } \\ \text { exchanger core }\left[\mathrm{m}^{2}\right]\end{array} & R \\ A_{\text {radial }} & \text { radial area of fin }\left[\mathrm{m}^{2}\right] & R_{f}\end{array}$

$A_{t} \quad$ total heat transfer area $\left[\mathrm{m}^{2}\right]$

$c_{p} \quad$ specific heat $[\mathrm{kJ} / \mathrm{kg} \cdot \mathrm{K}]$

$d \quad$ diameter $[\mathrm{m}]$

$f \quad$ friction factor

$g \quad$ gravitational acceleration $\left[\mathrm{m} / \mathrm{s}^{2}\right]$

$h \quad$ heat transfer coefficient $\left[\mathrm{W} / \mathrm{m}^{2} \mathrm{~K}\right]$

$h_{l v} \quad$ heat of fusion/vaporization $[\mathrm{kJ} / \mathrm{kg}]$

$k \quad$ thermal conductivity $[\mathrm{W} / \mathrm{m} \cdot \mathrm{K}]$

$L \quad$ length [m]

$\dot{m} \quad$ mass flow rate $[\mathrm{kg} / \mathrm{s}]$

$N \quad$ number (fins, thermosyphons)

$\mathrm{Nu} \quad$ Nusselt number

$P \quad$ Power (fan, pump) [W]

$p \quad$ pressure $[\mathrm{Pa}]$

$\operatorname{Pr} \quad$ Prandtl number

$q \quad$ heat transfer rate [W]
$q_{T S} \quad$ heat transfer of single thermosyphon [W]

corrected heat transfer of single thermosyphon [W]

$R \quad$ thermal resistance $[\mathrm{K} / \mathrm{W}]$

$R_{f} \quad$ thermal resistance of fin array

$[\mathrm{K} / \mathrm{W}], R=\frac{1}{A_{t} \eta_{t} \bar{h}}$

$R e_{d} \quad$ Reynolds number (diameter)

$R e_{d}=\frac{\rho \bar{U} d}{\mu}$

$R_{g} \quad$ Universal gas constant

$[\mathrm{J} / \mathrm{mol} \cdot \mathrm{K}]$

$S_{D} \quad$ spacing (diagonal) [m]

$S_{L} \quad$ spacing (longitudinal) [m]

$S_{T} \quad$ spacing (transverse) [m]

$T$ temperature $\left[{ }^{\circ} \mathrm{C}\right]$

$T_{e, \text { wall }}^{*} \quad$ corrected thermosyphon evaporator section wall temperature $\left[{ }^{\circ} \mathrm{C}\right]$

$t$

thickness [m]

U velocity $[\mathrm{m} / \mathrm{s}]$

$\dot{V} \quad$ volumetric flow rate $[\mathrm{kg} / \mathrm{s}]$

W $\quad$ width [m], work [J]

$X \quad$ correction factor

$x$

quality 


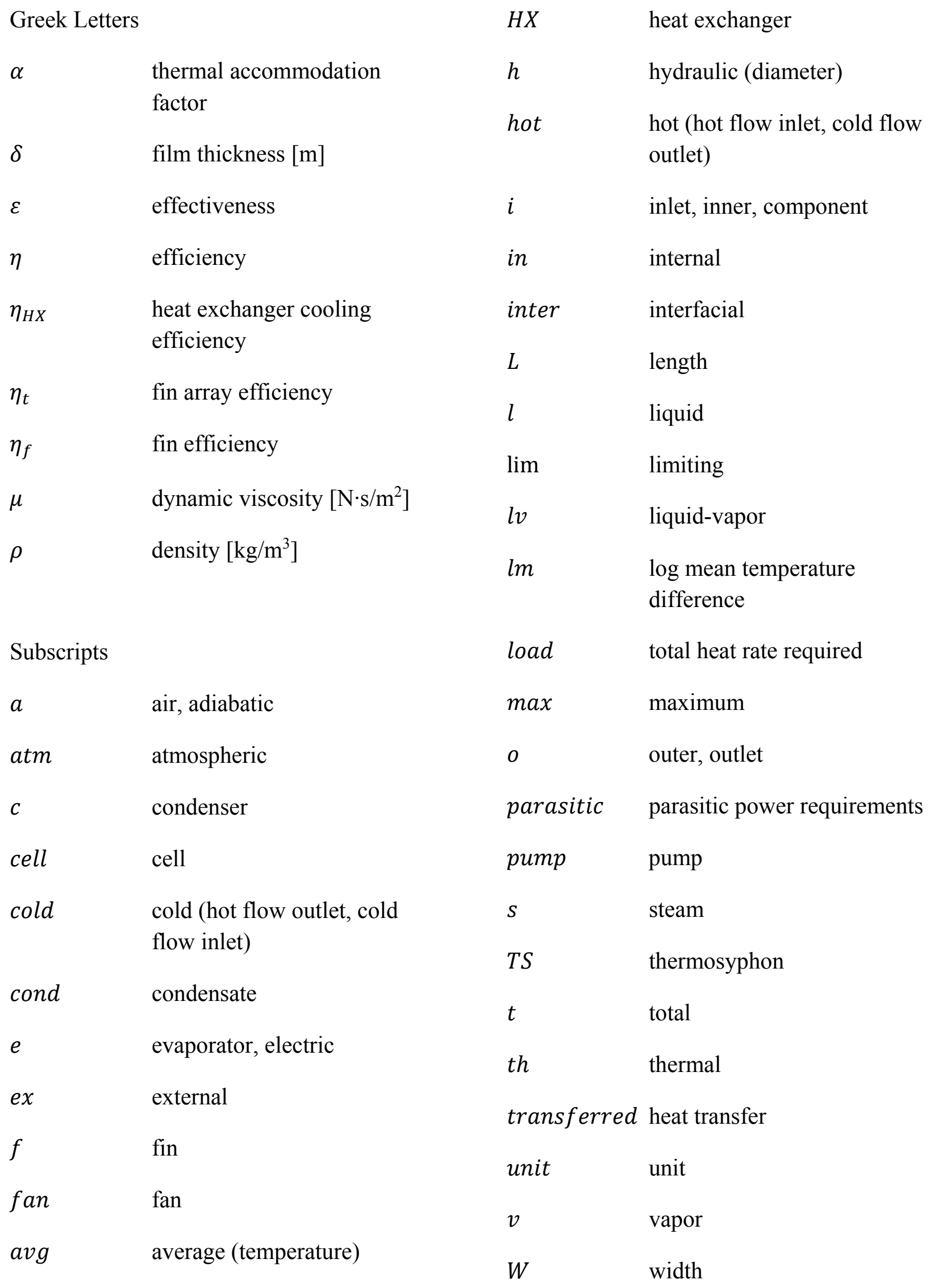


wall wall

Abbreviations

COP coefficient of performance

DDTSC direct dry thermosyphon

condenser

HPDC hybrid parallel direct

condenser

HSCT hybrid cooling tower

HPCT hybrid parallel cooling tower

IDTCT indirect dry thermosyphon

cooling tower

TS thermosyphon

TSHX thermosyphon heat exchanger 


\section{Introduction}

Thermoelectric power generation represents one of the primary uses of freshwater in the United States. In 2010, water requirements for thermoelectric power accounted for approximately $45.0 \%$ (161,000 Mgal/day) of all water consumption in the United States, with $38.0 \%$ of the water being freshwater (Maupin et al., 2010). Limiting water usage in thermoelectric plants allows for vital repurposing of freshwater that is otherwise lost to power production needs.

The current water shortages of Southern California have reinforced the need for an improved water infrastructure. According to Maupin et al. (2010), thermoelectric power requirements accounted for a water usage of $6,600 \mathrm{Mgal} /$ day (with $65.4 \mathrm{Mgal} /$ day being freshwater) in California alone. The drought effects in 2014 resulted in greater need for groundwater recovery, which required significant pumping costs and a corresponding reduction in viable land for agriculture. Estimated damages totaled a combined $\$ 2.2$ billion, with job losses of approximately 17,000 (Howitt et al., 2014). Furthermore, the limitations and ecological consequences of power plants that use once-through cooling are well recognized (Federal Water Pollution Control Act, 2011; California Energy Commission, 2013), and such plants are currently being phased out in favor of those using recirculation-cooling methods. The water needs of California and other areas with a fragile balance between water supply and consumption motivate the need for innovative and enhanced water saving technologies.

Thermoelectric power generation operates on the principles of either the Rankine or Brayton cycle, which use expansion of gases at high temperature and pressure through a turbine for the production of electricity. However, where the Brayton cycle uses combustion gases and a gas turbine, the Rankine cycle uses the combustion of fuel to provide phase change for a working fluid (usually water). The water vapor passes through the steam turbine, and is condensed, which involves heat rejection to an external fluid (again, usually water). There are two primary areas where improved heat transfer methods may promote water savings of a conventional Rankine-thermoelectric power plant using recirculation cooling: $i$ ) condensing the vapor after the steam turbine, and $i$ ) rejecting excess heat of the recirculated water flow.

Gravity-assisted thermosyphons and heat pipes are attractive devices for the effective cooling of thermoelectric power generation systems, and for integration in heat exchanger designs in general. Thermosyphons and heat pipes are passive devices that allow for exceptional heat transfer rates over large distances with little temperature gradient (Faghri, 1995). Conventional thermosyphons and heat pipes consist of a sealed container with a fixed quantity of fluid, which undergoes vaporization when heated in the evaporator section. The pressure driven vapor exits the evaporator section of the heat pipe, and passes through the adiabatic section, which offers nearly isothermal heat transport to the condenser section. The condenser section undergoes cooling, which provides heat rejection from the high temperature vapor flow and the simultaneous phase change (condensation) of the vapor to liquid. The condensed liquid is then 
returned to the evaporator section by either a gravity-assisted liquid film without the presence of a wicking structure (thermosyphons) or with the aid of a capillary pressure difference in a wick (heat pipes) (Faghri, 1995). Recent application of heat pipes has become increasingly important for cooling of portable electronics and energy systems (Faghri, 2014).

A thermal network approach for the transient analysis of heat pipes was conducted by Zuo and Faghri (1998) in which heat transfer in a conventional cylindrical heat pipe was described by six coupled differential equations. Shabgard et al. (2010) adopted the thermal network approach and investigated the effect of heat pipes for the potential performance enhancement of latent heat thermal energy storage systems. Shabgard et al. (2012) expanded on the previous work and applied the thermal network approach and an exergy analysis to a cascaded latent heat storage system for concentrating solar power applications.

Kunsagi et al. (1980) filed a patent for a heat exchanger using bent thermosyphons for condensing steam leaving a turbine. The hot stream (steam turbine exhaust) enters a lower flow channel, through which numerous thermosyphon evaporator sections extend. The steam is cooled and condensed on the thermosyphon evaporator ends, and condensate is removed for pumping to the boiler. Simultaneously, the latent heat of the hot steam flow is transferred to the thermosyphons and rejected to a forced convective flow of cooler, ambient air. Robertson and Cady (1980) presented the experimental set up and tested the viability of a scaled down thermosyphon heat exchanger as direct dry cooling for power plant applications. The experiment examined a direct condenser with 700 integrated thermosyphons and a $3 \mathrm{MW}_{\mathrm{e}}$ steam turbine.

Alternative direct dry cooling systems utilizing thermosyphons for enhanced heat transfer were patented by Fisher and Barnet (1983), and Brigida and Bow (1983). In the design patented by Fisher and Barnet (1983), the hot exhaust flow from the steam turbine rejects heat to the evaporator sections of thermosyphons, however, the condensed liquid is then returned to a pump and used as deluge water for further cooling of the un-finned thermosyphon condenser sections; a design much like a conventional wet cooling tower. In the patent filed by Brigida and Bow (1983), the condensed liquid was used as deluge water for an un-finned lower condenser section of the thermosyphons, while a forced convective flow of air was applied to the finned upper portion of the condenser section. Both designs result in evaporative losses of water vapor.

Robertson and Cady (1980) also discussed the possibility of a hybrid cooling system with indirect dry and wet cooling towers in series for enhanced cooling of the recirculation water. A parallel hybrid wet/dry cooling system was discussed which involved both dry and wet direct cooling of the exhaust steam, and an indirect wet cooling tower to cool the recirculating water for the direct steam condenser. The dry condenser is projected to work at times of low water availability, while the direct wet condenser would be operational when the water supply is sufficient, and when ambient temperatures are too high for efficient dry-cooling of condensate. 
Parts of China have readily adopted dry-cooling technology, with emphasis in the areas of commercial air-conditioning (Xuan et al., 2012a,b) and thermoelectric power plant cooling, particularly in the coal-abundant northwest (Xinjiang Uyghur Autonomous Region) (Warikoo, 2016). Ge et al. (2011) conducted experimental research on three full-scale direct air-cooled condenser units in operation in north China. Infrared thermography was used to find overall and local surface temperature distributions of the condenser units, and allowed for performance evaluation of the different flow configurations and operating conditions. Ge et al. (2011) identified that the counter-flow air-cooled dry condenser was prone to freezing in the winter, and revealed areas of reduced cooling due to uneven steam flow in the parallel flow configurations. Furthermore, the natural flow of ambient winds contributed to a flow vortex above the condensers, and caused hot air recirculation.

Novel engineering of existing dry condensers have proven their feasibility and robustness, particularly with respect to wind management and system response to ambient temperatures. Zhifu et al. (2005) conducted an experimental study pertaining to the disruptive effects of wind on an air-cooled condenser. The effects of wind direction, angle of incidence, and velocity were studied using flow dispersion on four 1:120 scale models of the dry condenser. The computational research by Liu et al. (2009) quantified the negative effects of hot air recirculation on an air-cooled condenser and expanded on the overall design suggestions of Zhifu et al. (2005), such as increased height of the perimeter wind-wall and increased rotational speed of peripheral fans. Kröger (2004), C. Kutscher and D. Costenaro (2002), and Maulbetsch (2012) discuss the deluge enhancement used by current dry condensers, which applies an exterior flow of cooling water to the hot condenser tubes to achieve the evaporative cooling typical to natural draft cooling towers during times of high ambient temperature.

Fouling is known to cause adverse effects on the potential heat transfer of a heat exchanger (Müeller-Steinhagen, 2000). The air-side tube bundles of current dry cooling applications are prone to particulate fouling, and thus require cleaning techniques. Narayanan (2010) obtained a patent for a spray cleaning system for use on current air-cooled condenser tubes. The system involves a cleaning mode of operation, in which de-mineralized condensate is diverted away from the normal power plant recirculation loop and repurposed as a cleaning fluid. The warm condensate is further pressurized by a separate water pump, and used to deluge the external airside tube surfaces. Narayanan (2010) also proposes heating of the existing condensate with hot steam from the turbine outlet, and effectively steam-cleaning the condenser system. Other common methods for cleaning of air-cooled condensers are presented by Putnam and Jaresch (2002), and include use of a firehose, a high pressure handlance, or automated cleaning machines.

To the best of our knowledge, there is no existing thermal analysis for the design of full-scale heat pipe/thermosyphon cooling of power plant systems. This work seeks to take a thermal resistance network approach for the analysis of various thermosyphon heat exchangers (TSHXs) and operating conditions, including the introduction of new concepts for dry cooling of large- 
scale electric power generators. Internal and external thermal resistances of the heat exchanger are considered for the thermal analysis of the condensation and cooling provided for a typical Rankine power cycle. An analytical method for the design of a heat exchanger is presented along with a parametric study. A detailed discussion includes thermal, hydrodynamic, coefficient of performance (COP), efficiency, and cost analyses, and suggests a modular design for all dry cooling systems with the integration of thermosyphons.

\section{Proposed Concepts}

Current Rankine-thermoelectric power plants reject the waste heat of the steam turbine exhaust vapor to an external fluid flow, most often water. In recirculation-cooled plants, this heated external flow of water is usually sent through a wet cooling tower which uses evaporative (latent) cooling to lower the temperature, and releases the converted water vapor to the environment. The remaining cooled liquid is then recirculated through the condenser unit, with supplemental fill-water to account for the mass losses of the vaporized water to the atmosphere. Due to design limitations, ecological concerns, and to comply with the ultimate elimination of once-through cooling systems, dry-cooling solutions have been proposed for integration with recirculation-cooled power plants.

The addition of heat pipes or thermosyphons to a heat exchanger may decrease the thermal resistance and increase the potential surface area for energy transfer between two media. Integration of modular banks of TSs are recommended, with three separately categorized heat exchanger systems: direct, indirect, and hybrid cooling systems. Each of the following systems have different benefits and drawbacks with respect to thermal performance, complexity, cost, and water consumption.

It may be noted that each of the following thermoelectric cooling concepts incorporates the use of extended surfaces on the exterior sections of the integrated thermosyphons/heat pipes. Traditional fins or novel conductive foams may be used to augment the total heat transfer of the system. Though extended surfaces represent additional thermal resistances, and the tight packing may lower local convective heat transfer coefficients, the drastic increase in surface area results in decreased total thermal resistance for each thermosyphon/heat pipe. However, a delicate balance between thermal design and financial limitations must be reached. While increased thermal performance may be attainable by simply adding material, it may not make economic sense. To this end, each design incorporates extended surfaces at the condenser (air-side) section of the thermosyphons/heat pipes, because heat transfer is generally limited by the low thermal conductivity of gases, as compared to that of liquids, and the lower energy transfer from sensible heat transfer compared to latent heat transfer. Minor surface area is added to the evaporator section for each dry cooling tower design (Concepts 2, 4 and 5) while the evaporator section is un-finned to aid in condensate run-off and return for direct condenser designs (Concepts 1 and 3). 


\subsection{Concept 1: Direct Dry Thermosyphon Condenser (DDTSC)}

In the proposed direct dry thermosyphon condenser (DDTSC), a bank of staggered thermosyphons acts in place of the existing tube assemblies of a conventional steam condenser (Figure 1). The evaporator section of each thermosyphon receives heat from the turbine exhaust, which is then rejected through the condenser section of the thermosyphon to a forced convective flow of air at ambient temperature. The DDTSC must transfer the same quantity of heat out of the condensing steam as in the conventional (wet) design, allowing for the complete phase change of the hot exhaust steam to a saturated liquid despite fluctuations in operating conditions.

\subsection{Concept 2: Indirect Dry Thermosyphon Cooling Tower (IDTCT)}

An indirect dry thermosyphon cooling tower (IDTCT) is illustrated in Figure 2 and is proposed as an alternative to a conventional indirect wet cooling tower. A conventional steam condenser rejects heat to the recirculation water loop, which is then cooled in the IDTCT, and piped back to the steam condenser. As previously described, traditional wet cooling towers consume water through evaporation to the atmosphere (as well as through blowdown and leakage). Because of the closed nature of the IDTCT, however, cooling is achieved using the transfer of sensible energy, and the working fluid undergoing phase change is internal to the thermosyphon; therefore evaporative loss of the recirculation water is avoided entirely. The IDTCT is comprised of a bank of staggered thermosyphons, with the evaporator sections extending into the warm recirculation fluid, with a forced convective flow of cool air directed to the condenser sections.

\subsection{Hybrid Wet/Dry Thermosyphon Cooling Systems}

\subsubsection{Concept 3 - Hybrid Parallel Direct Condenser (HPDC)}

A hybrid parallel configuration of a DDTSC and an existing steam condenser (HPDC) is proposed (Figure 3), to reduce the thermal load on the traditional wet steam condenser, as well as to minimize evaporative losses in the associated wet cooling tower. The parallel setup of the condenser units ensure the required condensation with less dependence on ambient conditions as compared to the stand-alone DDTSC (Figure 1) using variable steam mass flow rates to both dry and wet condensers.

\subsubsection{Concept 4 - Hybrid Series Cooling Tower (HSCT)}

Figure 4 illustrates a hybrid configuration where the IDTCT is placed in series before the existing wet cooling tower (as a pre-cooling tower). A benefit of this concept is the reduced 
water consumption from evaporative losses, with further cooling of the recirculation water achieved in the conventional wet cooling tower. A decreased temperature change between the wet tower inlet and outlet corresponds to a reduced cooling load, and correspondingly, lower water consumption.

\subsubsection{Concept 5 - Hybrid Parallel Cooling Tower (HPCT)}

The parallel configuration, shown in Figure 5, guarantees the same outlet temperature of the recirculation water leaving the cooling towers despite changes in ambient conditions. When the atmospheric temperature is low enough, all heat transfer can be achieved through the IDTCT. When conditions do not allow for optimal heat transfer (and therefore increased outlet temperature of the recirculation fluid) a portion of the flow is diverted to the conventional indirect wet cooling tower, reducing water consumption.

\section{Concept Advantages and Disadvantages}

The proposed thermosyphon heat exchanger systems share a number of similar advantages, with minimal drawbacks. The favorable thermal transport capabilities of the integrated thermosyphons allow for both the DDTSC and IDTCT concepts to operate at times of limited water supply, either in stand-alone or hybrid configurations. The total heat transferred by the dry condenser and dry cooling tower may also be managed by control of the forced convective air flow. At times of high energy generation, or when ambient conditions limit heat transfer through the DDTSC or IDTCT, the fan power may be increased, while conversely, air flow over thermosyphon banks may be reduced for lower power usage at lower ambient temperatures. Chance of freeze-up in the IDTCT is minimized through the use of the thermosyphon internal working fluid (water, ammonia, R134) is unlikely because the temperature at each section may be predicted at various operating conditions. Likewise, the IDTCT uses channel flow, characterized by large dimensions and volumetric flow rates of recirculating water which prevents freezing that may occur in conventional wet steam condensers that utilize numerous small-diameter pipe assemblies. Additionally, each design is largely fail-safe because of the minimal system dependence on the thermal transport of any singular thermosyphon. Current perceived disadvantages for all proposed systems are the increased manufacturing and installation costs associated with the thermosyphon and extended surface materials, although cost-reduction due to large-scale manufacturing, water savings, and low maintenance makes the DDTSC, IDTCT, and hybrid systems attractive prospects for thermoelectric cooling.

Each concept has its own distinct advantages and concerns. The stand-alone dry condenser (DDTSC, Concept 1) offers the cheapest design solution and removes the need for the recirculation loop and associated components (pumps, cooling towers, etc.). However, a complete retrofit of an existing power plant with a DDTSC is a disruptive installation process 
that would require full system shut-down. Alternatively, the IDTCT (Concept 2) allows for more easily-achieved retrofit. The IDTCT also allows for a greater log mean temperature difference between the steam turbine exhaust and the external heat rejection fluid flow, resulting in less cooling water required for the condensation of the steam, and therefore a lower pumping power, as compared to that required for a conventional cooling tower at the same operating conditions. The major disadvantage of the IDTCT design is that cooling may not be as efficient as the dry condenser, because of the transference of sensible heat, instead of latent heat from the phase change of the steam turbine exhaust vapor. As a result, significant additional surface area is required to achieve the same heat transfer rate.

Each hybrid system shares the same advantages as the specific, stand-alone components involved (i.e. the DDTSC and IDTCT concepts), however, the disadvantages are minimized. In the proposed hybrid parallel direct condensers (Concept 3), full condensation of the turbine exhaust steam is possible at all times, because of the shared thermal load between the DDTSC and wet steam condenser. The hybrid series cooling towers (Concept 4 ) enable greater cooling of the heat rejection stream, and an increased log mean temperature differential between the hot steam from the turbine exhaust and the cooling water of the steam condenser. Similarly, the hybrid parallel cooling towers (Concept 5) can ensure a constant outlet temperature of the recirculation fluid, and therefore minimizes fluctuations in overall power plant efficiency. The mass flow rates of the heat rejection flow to either the IDTCT or wet cooling tower may be managed in times of limited water supply or non-ideal atmospheric conditions to provide the same cooling as in other operating conditions. The significant disadvantage of any hybrid system is in the increased cost of manufacturing and installing more power plant components.

\section{$4 \quad$ System Description}

The direct dry condenser and indirect dry cooling tower will both be analyzed using a hierarchical design in order to guarantee a heat exchanger performance that fulfills the required demands. There are three levels of organization related to the configuration of each heat exchanger:

- A module

- A unit

- The system

The simplest subset of the system is referred to as a module and consists of a single thermosyphon embedded in both the heat rejection water flow and in the cooling air flow (Figure 6). Each module is assumed to be geometrically identical, and likewise demonstrate the same flow and heat transfer behavior as the other modules surrounding it. Furthermore, each module is considered independent of all other modules. 
A unit of the DDTSC and IDTCT is defined as a geometric arrangement of thermosyphon modules, placed in a staggered grid of particular length, width and height. The arrays of thermosyphons are in crossflow with both the heating water and cooling air flows (Figure 7). It should be noted that because the water and air flows are perpendicular to one another (Figure 8), the transverse spacing of the thermosyphons on the hot-side of the heat exchanger is equivalent to the longitudinal spacing on the air-side of the heat exchanger. Similarly, the longitudinal spacing of the thermosyphons on the hot-side of the system translates to the transverse spacing with respect to the air flow direction. As with the module, the flow and heat transfer behavior within a single unit is considered to be uniform for all units, and independent of those around it.

It is reinforced that no adiabatic sections are considered for the thermosyphons, and that heat conduction through the separating plate (Figure 6) is neglected. However, it should be emphasized that the conductive separating plate will serve to increase the heat transfer of each system by adding surface area between the hot and cold flows. Heat transfer through the separating plate may be predicted using conventional heat exchanger analysis. In this study, the benefit of thermosyphons as the dominant method of heat transfer is investigated, and accordingly the heat transfer (and cost) associated with the separating plate is neglected.

The overall DDTSC and IDTCT systems are represented in Figure 1 and Figure 2. Each system is composed of identical units and modules of thermosyphons as previously described. In addition, the flow of air in either system is illustrated in greater detail in Figure 9.

\section{$5 \quad$ Model Validation}

The predicted DDTSC (Concept 1) performance is to be compared to an existing direct dry cooling system for design validation. The Walter M. Higgins Generating Station in Primm, Nevada is a $550 \mathrm{MW}_{\mathrm{e}}$ natural gas power plant that uses a pair of efficient combustion turbines for the production of energy. In addition, exhaust gases are used to power a steam turbine, which uses an air-cooled direct dry condenser to provide the phase change necessary for the traditional Rankine power cycle. The power plant is heralded for its (near) dry cooling system that uses $7 \%$ of the water used by conventional water-cooled power plants (NVEnergy, 2014). The condenser uses a forced convective flow of air across finned tube bundles through which the exhaust steam flows. However, fan power, noise, size, and reduced efficiency of the overall Rankine cycle (due to the higher temperatures required at the condenser) are major problems with current direct dry condensers. An illustration of the existing system with a number of key input and output parameters is given in Figure 10.

The performance goals for dry cooling systems are provided by the U.S. Department of Energy (2014) for non-metallic systems, and are included in Table 1. Because thermosyphons utilize more than one heat transfer surface material (the metallic outer surface and inner working 
fluid), any heat exchanger with integrated thermosyphons is considered to be a non-metallic system.

\section{Thermal Network Methodology}

The thermal network for a single thermosyphon (module) is illustrated in Figure 11. The following equations are presented to quantify each thermal resistance internal and external to each thermosyphon. For clarity, the resistances are considered separately for the evaporator and condenser sections, respectively. The thermal resistances associated with the adiabatic section $\left(R_{a, w}\right.$ and $\left.R_{a, i n}\right)$ are not considered in the present analysis. It should be clarified that while Figure 1 shows inclined thermosyphons for the DDTSC setup, the current analysis of both the DDTSC and IDTCT focuses on vertically-oriented thermosyphons, to ensure stability and normal operation. Inclined thermosyphons may be prone to dryout in the evaporator section (Kim and Kim, 1995; Kudritskii, 1994).

\subsection{Thermosyphon evaporator side}

\subsubsection{External thermal resistance due to heat source, $\boldsymbol{R}_{e, e x}$}

The DDTSC utilizes the latent heat of condensation for heat transfer external to the thermosyphon evaporator. The corresponding average heat transfer coefficient $\bar{h}_{e, \text { ex }}$ can be obtained using the expression for condensation on a vertical flat plate, given by Faghri and Zhang (2006):

$$
\overline{N u}_{e, e x}=\frac{\bar{h}_{e, e x} L_{e}}{k_{l}}=0.943\left[\frac{\rho_{l}\left(\rho_{l}-\rho_{v}\right) g h_{l v} L_{e}^{3}}{\mu_{l} k_{l} \Delta T}\right]^{1 / 4}
$$

where $\Delta T$ is the difference in temperature between the saturation temperature of the steam and the wall. Equation 1 may be applied to condensation external to a vertical tube if $\delta / D \ll 1$, where $\delta$ is the film thickness of the condensate (Faghri and Zhang, 2006):

$$
\delta=\left[\frac{4 k_{l} \mu_{l} \Delta T}{\rho_{l}\left(\rho_{l}-\rho_{v}\right) g h_{l v}}\right]^{1 / 4} \cos (\theta)
$$

For the current analysis, each DDTSC (and IDTCT) unit consists of vertical thermosyphons; however, the analysis can be extended for designs using inclined thermosyphons by applying a correction factor. In this case, the $\cos (\theta)$ term accounts for the inclination of the system away from vertical.

The IDTCT uses convective heat transfer to the evaporator section of the thermosyphon, described by the Nusselt correlation for flow across a bank of finned tubes (Schmidt, 1988; Kearney and Jacobi, 1995): 


$$
\overline{N u}_{e, e x}=\frac{\bar{h}_{e, e x} d_{o}}{k_{e, e x}}=0.45\left(\frac{A_{t, e}}{\pi d_{o} L_{e}}\right)^{-0.375} \overline{R e}_{d}{ }^{0.625} \operatorname{Pr}_{e, e x}{ }^{1 / 3}
$$

where all properties are taken at the average temperature of the external fluid flow, and $A_{t}$ is simply the total heat transfer surface area of the evaporator section. For any finned surface (evaporator/condenser), the total heat transfer area is calculated as:

$$
A_{t}=\pi d_{o}\left(L-N_{f} t_{f}\right)+N_{f} A_{f, \text { radial }}
$$

and,

$$
\eta_{t}=1-\frac{N_{f} A_{f, \text { radial }}}{A_{t}}\left(1-\eta_{f}\right)
$$

For any un-finned section, including the DDTSC evaporator section, the fin array efficiency $\eta_{t}$ is unity. The average thermal resistance associated with each region of the thermosyphon may then be calculated using the corresponding average convection coefficient.

\subsubsection{Radial conduction through the evaporator wall, $\boldsymbol{R}_{e, w}$ :}

The thermal resistance attributed to conduction through the wall of the evaporator region of the thermosyphon is described by Fourier's law. For a conventional cylindrical thermosyphon, the resistance is then:

$$
R_{e, w}=\frac{\ln \left(d_{o} / d_{i}\right)}{2 \pi L_{e} k_{w}}
$$

\subsubsection{Internal evaporation resistance in the evaporator, $\boldsymbol{R}_{e, i n}$ :}

To obtain the ideal heat transfer in each thermosyphon, an optimal filling ratio is assumed, which corresponds to a liquid pool area of zero and a liquid film that extends along the entire length of

the thermosyphon. The average heat transfer coefficient $\bar{h}_{e, i n}$ describes the evaporation from the liquid film (Faghri, 1995; Strel'tsov, 1975):

$$
\bar{h}_{e, \text { in }}=\frac{4}{3}\left[\frac{\rho_{l}^{2} k_{l}^{3} g h_{l v}}{4 \mu_{l}\left(T_{w, e}-T_{v, \text { sat }}\right) L_{e}}\right]^{1 / 4}
$$

\subsubsection{Interfacial resistance in the evaporator, $\boldsymbol{R}_{e, \text { inter }}$ :}

The interfacial resistance due to the pressure difference across the liquid-vapor interface in the evaporator section of a thermosyphon can be calculated, where the interfacial heat transfer coefficient, $\bar{h}_{e, \text { inter }}$, is approximated using the correlation from Faghri and Zhang (2006): 


$$
\bar{h}_{e, \text { inter }}=\left(\frac{2 \alpha}{2-\alpha}\right)\left(\frac{h_{l v}^{2}}{T_{v} v_{l v}}\right) \sqrt{\frac{1}{2 \pi R_{g} T_{v}}}\left(1-\frac{\bar{p}_{v} v_{l v}}{2 h_{l v}}\right)
$$

where $\alpha$ is an accommodation factor of value between 0 and 1 , and is dependent on both the surface and vapor properties (Goodman, 1967). In the current study, an $\alpha$ value of 1.0 is used as the limiting case corresponding to the maximum thermal resistance.

\subsection{Thermosyphon vapor core}

\subsubsection{Vapor resistance in the core, $R_{v}$ :}

Axial resistance of the vapor core due to the pressure drop across the length of the thermosyphon is normally minimal and regarded as negligible. However, for greater accuracy, it is included in the calculation of the total thermosyphon internal resistance. The original equation for the pressure drop due to the vapor flow in the axial direction is given by Faghri (1995), and expressed as a thermal resistance by Shabgard et al. (2015):

$$
R_{v}=\frac{8 R_{g} \mu_{v} T_{v}^{2}}{\pi h_{l v}^{2} \bar{p}_{v} \rho_{v}}\left[\frac{\left(L_{e}+L_{c}\right) / 2+L_{a}}{\left(d_{i} / 2\right)^{4}}\right]
$$

\subsection{Thermosyphon condenser side}

\subsubsection{Interfacial resistance in the condenser, $R_{c, i n t e r}$ :}

As for the evaporator side, the interfacial resistance of a single thermosyphon is calculated with

the condenser side interfacial convection coefficient, $\bar{h}_{c, \text { inter }}$, obtained using Eq. 8 (Faghri and Zhang, 2006).

\subsubsection{Internal condensation resistance in the condenser, $\boldsymbol{R}_{c, i n}$ :}

The average internal convection coefficient of the liquid film in the condenser section, $\bar{h}_{c, i n}$, can be identified using a Nusselt correlation for condensation on a vertical flat plate assuming a constant heat flux (Faghri, 1995; Faghri and Zhang, 2006; Faghri et al., 2010; Shabgard et al., 2015):

$$
\bar{h}_{c, \text { in }}=1.71\left[\frac{g \rho_{l}\left(\rho_{l}-\rho_{v}\right) k_{l}^{3} h_{l v}\left(d_{i} / 2\right)}{\mu_{l} q_{\mathrm{TS}}}\right]^{1 / 3}
$$




\subsubsection{Radial conduction through the condenser wall, $\boldsymbol{R}_{c, w}$}

The conduction through the wall of the condenser region similarly follows Fourier's law, and for a cylindrical thermosyphon can be described by Eq. 6, where the length is that of the thermosyphon condenser section.

\subsubsection{External thermal resistance due to heat sink, $R_{c, e x}$ :}

Both the DDTSC and IDTCT use finned condenser sections of known dimensions, with the thermal resistance of the external flow on the condenser side calculated using the same method as done for the evaporator side (Eqs. 3-5).

It is assumed that the thermal resistances associated with the adiabatic section of each thermosyphon $\left(R_{a, w}\right.$ and $\left.R_{a, i n}\right)$ are infinitely large (Figure 11). Therefore, there is negligible axial heat transfer through the wall and liquid film of each thermosyphon, and the total thermal resistance $R_{T S}$ per module is then simply:

$$
R_{T S}=\sum R_{i}=R_{e, e x}+R_{e, w}+R_{e, \text { in }}+R_{e, \text { inter }}+R_{v}+R_{c, \text { inter }}+R_{c, \text { in }}+R_{c, w}+R_{c, e x}
$$

\section{$7 \quad$ Solution Procedure}

The thermosyphon resistances are calculated as discussed in Section 6. The height and width of each heat exchanger unit are inputs to the system. Additionally, the number of thermosyphons in each unit, $N_{T S \text {, unit }}$, may be calculated based on the unit dimensions, as well as the thermosyphon and fin sizes and geometric arrangement.

Though the resistances can be determined using the preceding correlations, the operating temperature of each thermosyphon is still unknown. Using a lumped mass approach, the temperatures of the exterior cooling flow of water, the evaporator wall, liquid film (in the evaporator), interior vapor, liquid film (in the condenser), condenser wall, and outlet air flow can be calculated. For identification of the component temperatures, the thermophysical properties

$\left(k_{w}, k_{l}, \rho_{l}, h_{l v}, \mu_{l}, \mu_{v}, \rho_{v}\right)$ associated with the heat pipe are assumed constant, and are taken at an average of the cooling water and ambient air temperature, with the cooling water temperature approximated as the average temperature between the inlet and outlet:

$$
T_{\text {avg }}=\frac{\left[\frac{\left(T_{h o t, i}+T_{h o t, o}\right)}{2}+T_{\text {cold }, i}\right]}{2}
$$

Because of the small temperature drop experienced by heat pipes and thermosyphons, and the steady-state nature of this study, the operating temperature of the heat pipe does not change 
drastically for the given inlet and outlet conditions. The assumption of constant properties is therefore considered to be acceptable.

Both the hot-side flow and cold air flow are assumed to be incompressible, fully-developed, and with constant properties and velocity throughout. Furthermore, each module and unit are considered to have identical flow behavior and heat transfer, with zero heat loss to the environment except through the finned-condenser sections. Radiative heat transfer to and from each system is considered negligible, because of the relatively low temperatures of the hot and cold flows, as well as the ambient.

\subsection{Thermosyphon Component Temperatures}

The inlet and outlet temperatures of the hot-side of the heat exchanger are both specified. The temperature of the fluid external to the evaporator section of each thermosyphon is approximated as the average temperature of the hot-side inlet and outlet temperature. An initial prediction of the evaporator wall temperature, $T_{e, w a l l}^{*}$, is estimated and increased incrementally, with the ambient temperature as the lower limit, and the hot-side inlet temperature as the upper limit. The total heat transfer to the thermosyphon, $q_{T S}^{*}$, is based on the temperature difference between the hot-side inlet and outlet, and the estimated temperature of the evaporator wall:

$$
q_{T S}^{*}=\left(\frac{T_{h o t, i}+T_{h o t, o}}{2}-T_{e, w a l l}^{*}\right) / R_{e, e x}
$$

Corresponding temperature drops across the thermosyphon components are then solved for as the product of the calculated thermal resistances (Section 6) and the estimated heat transfer rate:

$$
\Delta T_{i}=R_{i} q_{T S}^{*}
$$

where the subscript $i$ refers to the thermosyphon section (evaporator wall, liquid film, etc.).

The accuracy of the estimated evaporator wall temperature is still unknown; thus the log mean temperature difference for a bank of tubes in cross flow is computed. The correlation for the temperature change across unfinned tubes is given by (Bergman et al., 2011):

$$
\frac{T_{c, \text { wall }}-T_{\text {cold }, o}}{T_{c, \text { wall }}-T_{\text {cold }, i}}=\exp \left(-\frac{\pi D N_{T S, u n i t} \bar{h}_{c, e x}}{\rho U_{\text {cold }, i} N_{T S, W} S_{T} c_{p}}\right)
$$

where $\bar{h}_{c, e x}$ is the average convection coefficient of the external air flow (Section 6.3.4).

The term $N_{T S, \text { unit }}$ is the total number of thermosyphons per unit, and is calculated differently for the two systems. The length of one unit, $L$, is fixed for the DDTSC but not for the IDTCT. Conversely, the velocity of the hot water flow, $U_{h o t, i}$, is fixed for the IDTCT, and not for the DDTSC. In addition, the longitudinal and transverse spacing of the thermosyphons in a unit are 
specified. By fixing the length of a single unit of the DDTSC, the log mean temperature difference can be estimated:

$$
N_{T S, u n i t}=N_{T S, W} N_{T S, L}=\frac{W}{S_{T}} \frac{L_{u n i t}}{S_{L}}
$$

For the DDTSC, the length of one unit is used as a fixed input because of the convergence requirements of the solution method. The length of the system is required in Eq. 15 due to the dependence of $N_{T S \text {, unit }}$ on the length of the unit (Eq. 16). Alternatively, the hot-side mass flow rate of the IDTSC is immediately required for calculation of the heat transfer to a single thermosyphon. The correlation describing the heat transfer to a finned bank of tubes (Eq. 3) is dependent on the Reynolds number of the hot-side water flow. In contrast, the condensation of liquid on the evaporator sections of the DDTSC is predicted by Eq. 1, and is independent of mass flow rate.

The length of the IDTCT unit is determined by the total number of units in the system, which is dependent on the ratio of the total hot-side mass flow rate to the mass of hot flow of water in one unit:

$$
N_{\text {unit }}=\frac{\dot{m}_{\text {hot }, t}}{\dot{m}_{\text {hot }, \text { unit }}}=\frac{q_{\text {load }} / c_{p, h o t}\left(T_{\text {hot }, i}-T_{\text {hot }, o}\right)}{\rho_{\text {hot }} U_{\text {hot }, i} A_{\text {hot }, i}}=\frac{q_{\text {load }} / c_{p, h o t}\left(T_{\text {hot }, i}-T_{\text {hot }, o}\right)}{\left(\rho_{\text {hot }} U_{\text {hot }, i n} W L_{e}\right)}
$$

and,

$$
N_{T S, \text { unit }}=\frac{N_{T S}}{N_{\text {unit }}}=\frac{q_{\text {load }} / q_{T S}^{*}}{N_{\text {unit }}}
$$

The length of one unit of the IDTCT is then obtained from $L=\left(N_{T S, u n i t} / N_{T S, W}\right) S_{L}$. With the number of thermosyphons predicted for the dry condenser and dry cooling tower (Eqs. 16 and 18, respectively), the outlet temperature of the cold-side flow of air can be predicted from Eq. 15.

The log mean temperature difference for each system is then calculated using the correlation for a counter-flow heat exchanger (Bergman et al., 2011):

$$
\Delta T_{l m}=\frac{\left(T_{\text {hot }, i}-T_{\text {cold }, o}\right)-\left(T_{\text {hot }, o}-T_{\text {cold }, i}\right)}{\ln \left[\frac{T_{\text {hot }, i}-T_{\text {hot }, o}}{\left.T_{\text {hot }, o}-T_{\text {cold }, i}\right]}\right]}
$$

The heat transfer rate in a single thermosyphon/module is obtained by using the log mean temperature difference calculated in Eq. 19:

$$
q_{T S}=\frac{\Delta T_{l m}}{R_{T S}}
$$

The heat transfer rate for the heat exchanger (Eq. 20) is then used to determine whether the predicted heat transfer and the estimated evaporator wall temperature is correct. The difference between the heat rate based on the log mean temperature difference and that using the estimated 
evaporator wall temperature is compared and is considered converged when they are within a set tolerance of $10 \mathrm{~W}$ :

$$
\left|q_{T S}-q_{T S}^{*}\left(T_{e, w a l l}^{*}\right)\right| \leq 10 \mathrm{~W}
$$

Additionally, the saturation vapor temperature of the thermosyphon is adjusted to the new vapor temperature. If the convergence criteria is not satisfied, the evaporator wall temperature is increased by a small step size, and the thermal resistances and heat transfer associated with the thermosyphon are recalculated.

\subsection{Performance Parameters}

The net power production of the Rankine cycle depends on both the pump power and fan power required for the heat exchanger concepts. It should be noted that this analysis does not include the power required by the pump which delivers condensate to the boiler. Because the heat exchanger concepts use the same Rankine cycle inputs, the boiler feedwater pump powers are considered equal.

Unlike the IDTCT, the flow external to the evaporator section of the DDTSC is hot water vapor, which condenses on the surface of unfinned tubes. The pressure drop is supplied by the expansion of the hot vapor across the turbine, and therefore does not require any external pumping or fan power. Furthermore, the phase-change occurring in a conventional Rankine cycle condenser is near-isobaric, and the pressure drop is considered negligible.

The air-side pressure drop of the DDTSC uses the friction factor $f$ recommended by Robinson and Briggs (1966) and redefined by Kearney and Jacobi (1995) for a finned staggered array of circular tubes:

$$
\frac{f}{N}=18.93\left(\frac{2 A_{C}}{A}\right)\left(\frac{S_{T}}{d_{o}}\right)^{-0.927}\left(\frac{S_{T}}{S_{D}}\right)^{0.515} R e_{d, \max }^{-0.316}
$$

where $N$ is the number of rows of tubes perpendicular to the flow of air, $A_{c}$ is the minimum free flow area of the heat exchanger core, and $A$ is the total heat transfer area at the same transverse plane, and $S_{D}$ is the diagonal spacing (Figure 7) of the heat exchanger, $S_{D}=\left[S_{L}^{2}+\left(\frac{S_{T}}{2}\right)\right]^{1 / 2}$. The maximum Reynolds number of the flow is obtained using the theoretical maximum velocity of the flow, which occurs in the transverse plane (Bergman et al., 2011), where $U_{\max }$ is:

$$
U_{\max }=\frac{s_{T}}{S_{T}-d_{o}} U
$$

Bergman et al. (2011) reports that Nusselt numbers calculated by Žukauskas and Ulinskas (1988) and Grimison (1937) using the prescribed adjustment to the velocity of the flow (and the 
resulting Reynolds numbers) were within 15\%. The maximum pressure drop for flow across a finned bank of tubes is then obtained from the correlation of Žukauskas and Ulinskas (1988):

$$
\Delta p=f\left(\frac{L_{u n i t}}{d_{h}}\right)\left(\frac{\rho U_{\max }{ }^{2}}{2}\right)
$$

where $d_{h}$ is the hydraulic diameter of the channel. The power required to drive the flow of water in the IDTCT and the cool air flows of both systems are both calculated by:

$$
P=\dot{W}=\frac{\dot{V} \Delta p}{\eta}
$$

where $\eta$ is the fan or pump efficiency depending on which flow and which system is being considered.

To better describe the overall performance of each heat exchanger concept, the effectiveness $(\varepsilon)$, coefficient of performance (COP), total cost, and cost per $\mathrm{kW}_{\text {th }}$ is obtained. The effectiveness of the heat exchanger is obtained for both the DDTSC and IDTCT concepts by:

$$
\varepsilon=\frac{q}{q_{\max }}
$$

where $q$ is the actual heat transfer of the system, and $q_{\max }$ is the maximum possible heat transfer. The heat transfer of the system is designed to meet the design requirement of 730 $\mathrm{MW}_{\mathrm{th}}$, and is calculated as described in Section 7.1. However, the maximum predicted heat transfer occurs if there are no external thermal resistances of either the hot or cold flows $\left(R_{e, e x}\right.$ and $\left.R_{c, e x}\right)$, respectively. In that case, the only temperature drop would be due to the internal heat transfer and flow dynamics of the thermosyphons. The maximum heat transfer of one thermosyphon is therefore:

$$
q_{\max }=\frac{\Delta T_{l m}}{R_{T S}-\left(R_{e, e x}+R_{c, e x}\right)}
$$

For each hybrid system, the thermal load on the proposed dry condenser/cooling tower is halved, and the existing wet cooling tower receives the remaining heat load of the system (365 $\mathrm{MW}$ th each). The maximum possible heat transfer is still considered to be the total thermal load of $730 \mathrm{MW}_{\text {th. }}$.

The coefficient of performance (COP) for the DDTSC and IDTCT, as well as the hybrid concepts (HPDC, HSCT and HPCT) can be written in terms of the ratio of total heat transferred to the combined power required for the pump $\left(P_{\text {pump }}\right)$ and fan power $\left(P_{f a n}\right)$, where the DDTSC requires no hot-side fan or pump work. The hybrid systems also include the additional pump power required for the conventional wet cooling components. The coefficient of performance for all systems can be summarized as the rate of thermal energy transferred by the heat exchanger $Q_{t h}$, to the amount of parasitic work used by auxiliary devices (pumps and fans): 


$$
\mathrm{COP}_{H X}=\frac{Q_{t h}}{P_{\text {fan }}+P_{\text {pump }}}
$$

The heat exchanger cost is estimated by considering the ratio of total cost to $\mathrm{kW}_{\text {th }}$ transferred. The total volume of stainless steel for the thermosyphon containers and the total volume of aluminum used as fin material were calculated for a cylindrical thermosyphon container and annular fins, respectively. The total weight of the steel and aluminum were then obtained and the total cost of the heat exchanger was calculated based on the current bulk prices of stainless steel pipe and aluminum (\$1.00/kg and $\$ 1.50 / \mathrm{kg}$, respectively) (MetalPrices.com, 2015). A manufacturing factor may be included to adjust costs associated with manufacturing and changes in the prices of the raw materials, however, for the bulk cost of materials, no scaling of the total cost is applied, and the total cost is reflective of that for raw materials only.

The cooling efficiency is desired for comparison between each proposed system and existing wet-cooled plants of similar heat load. The efficiency of a cooling tower is calculated by (Gao et al., 2016)

$$
\eta_{H X}=\frac{T_{i}-T_{o}}{T_{i}-T_{\lim }}
$$

where the subscripts $i$ and $o$ refer to the flow inlet and outlet, respectively, and $T_{\text {lim }}$ is the limiting low temperature of the flow, which is equal to the wet bulb temperature of the ambient air. For the DDTSC, it is assumed that steam enters as a saturated vapor, and exits as a saturated liquid, with no significant change in temperature. Therefore, the cooling efficiency is calculated based on the inlet and outlet temperatures of the cooling air flow.

The hybrid designs (Concepts 3-5) use average estimated values for the total costs of the wet cooling components for dissipation of $730 \mathrm{MW}_{\text {th }}$, given by Tsou et al. (2013). Accordingly, a conventional steam condenser involved in the design is assigned a cost of $\mathrm{M} \$ 1.75$, and a conventional wet cooling tower is priced at M\$8.50. Predicted costs for the wet cooling components handling half the thermal load (365 $\mathrm{MW}_{\text {th }}$ ) are similarly half the cost as those handling the full load $(730 \mathrm{MW}$ th). Water loss is predicted from the fraction of the total mass flow rate of recirculation water to a conventional cooling tower. Tsou et al. (2013) provides that the water loss of a similarly sized thermoelectric power plant utilizing the Rankine cycle is 315 $\mathrm{kg} / \mathrm{s}$, for a recirculation mass flow rate of $15,800 \mathrm{~kg} / \mathrm{s}$.

Based on the simplifications and the dependence of the solution on empirical or semiempirical correlations, the size and performance of the system are predicted values and may not accurately represent an actual system that is subject to fluctuations in ambient conditions, nonuniform flow and heat transfer, and fouling. The calculation of thermal resistances, pressure drops, and performance parameters for each system are intended for an initial feasibility study, and deviation from actual performance is expected. 


\section{Results}

A comprehensive system description for both the dry DDTSC and IDTCT is given in Table 2. The dimensions, material, and working fluid of the integrated thermosyphons are presented. The system-level parameters including the thermal energy load and efficiencies of each component are included, along with the specifications of each concept at the unit and modular levels. Additionally, the hot and cold-side input temperatures and flow rates are shown for each system. Note that the isothermic condensation is reflected by the inlet and outlet temperatures of the DDTSC. Furthermore, a condensing temperature higher than the hot outlet of the IDTSC is required, which is consistent with a condensation temperature of $57.2^{\circ} \mathrm{C}$ for existing dry cooling systems (Tsou et al., 2013).

It should be noted that the difference in input parameters and solution method for both systems is reflected in Table 2. The length of one unit is an input to the DDTSC. Conversely, the velocity of the hot water is an input to the IDTCT.

\subsection{System Feasibility}

System inputs and the obtained results describing the dimensions, flow dynamics, and thermal behavior of both the direct condenser and indirect cooling tower are summarized in Table 2 . The pressure drops for the DDTSC and IDTCT are used to determine the parasitic power requirements (fan and pump power) and can be directly compared for both systems. It can be seen that the air flow of the direct condenser undergoes a larger pressure drop (5.48 Pa) than the dry cooling tower $(1.23 \mathrm{~Pa})$ which is reflected in the increased fan requirements for the DDTSC (1.93 $\mathrm{MW}_{\mathrm{e}}$ for the DDTSC, as compared to $0.19 \mathrm{MW}_{\mathrm{e}}$ required for the IDTCT). Furthermore, the calculated heat transfer coefficients for both external flows are presented, as well as the thermal resistances of each component. The temperature of each thermosyphon component is not included, but can be obtained from the thermal resistance, the heat rate of one thermosyphon, and the solution method presented in Section 7.1. The effective internal thermal resistance of each thermosyphon was $6.7^{\circ} \mathrm{C} / \mathrm{kW}$ and $0.90^{\circ} \mathrm{C} / \mathrm{kW}$ for each system using the DDTSC and IDTCT as component system, respectively. This corresponds to effective internal thermal conductivities of $0.15 \mathrm{~kW} /{ }^{\circ} \mathrm{C}$ and $1.11 \mathrm{~kW} /{ }^{\circ} \mathrm{C}$, respectively.

A quantitative analysis for the overall feasibility of the dry condenser and dry cooling tower is best considered in terms of the power and performance indicators of Table 1. The total cost and cost per $\mathrm{kW}$ th, as well as the coefficient of performance and effectiveness of both the DDTSC and IDTCT are presented in Table 2. 
The cost depends significantly on the system design. It can be seen that the dry condenser (DDTSC) estimated cost is M $\$ 22.62$, which is less than that of the indirect cooling tower (IDTCT), which is projected to be $\mathrm{M} \$ 39.08$. Overall, the total thermal resistance of one module (or thermosyphon), $R_{T S}$, is almost $19.1 \%$ lower for the dry condenser. Also, because the DDTSC has an unfinned evaporator section, the cost associated with augmented heat transfer surface is absent, contributing to cost savings on a per module basis. However, as previously described, the cost saving predicted for the DDTSC must be weighed against the more intensive and disruptive installation required, compared to that of the IDTCT.

The cost per $\mathrm{kW}_{\mathrm{th}}$, coefficient of performance (COP), and the effectiveness are each used to gage the feasibility of each design. All parameters are near or above the standards required for dry cooling systems, given in Table 1. (U.S. Department of Energy, 2014). The COP best illustrates the parasitic power requirements of the peripheral fan and pump units. The increased thermal resistance of an IDTCT module, and corresponding increase in the length of the system (based on number of thermosyphons), results in a far greater pump power requirement as compared to the DDTSC, which conversely has a significantly higher fan requirement than the IDTCT.

The effectiveness compares the actual amount of heat transfer to the maximum theoretical value for a particular heat exchanger. By assuming an adiabatic separating plate between the hot and cold flows, the maximum theoretical heat transfer would occur if the external resistances to the thermosyphon evaporator and condenser regions were negligible. It can be seen that the direct condenser has a relatively high COP but has an effectiveness $(0.55)$ that is slightly lower than the goal of 0.6 .

A similar analysis is presented for the series and parallel arrangements (Concepts 3-5) of the dry condenser and cooling tower in Table 3. As done for the DDTSC and IDTCT, the system inputs and results are included, along with the performance evaluators used to assess the feasibility of each system. To fully describe each system, a number of different design inputs are considered. As part of the analysis, the total heat load on each system component is given. It can be seen that the dry condenser in parallel with the existing steam condenser (HPDC) is designed to handle half of the total heat rejection load ( $\left.365 \mathrm{MW}_{\text {th }}\right)$ with the remaining heat load placed on the wet condenser. The dry cooling towers integrated into the HSCT and HPCT designs are also designed for heat rejection of $365 \mathrm{MW}_{\text {th }}$, with conventional wet cooling towers rejecting the remaining $365 \mathrm{MW}_{\text {th. }}$. For each of the systems that are designed to co-exist with wet-cooling structures, the total mass flow rate of the hot water of the Rankine cycle is distinctly separated from the recirculation water mass flow rate. It should be noted that the mass flow rates are total values, and that for the hybrid parallel direct condenser (HPDC), the dry condenser and existing wet condenser both receive half of the total mass flow rate of hot steam exiting the turbine. Likewise, for the hybrid parallel cooling tower (HPCT) concept, the dry condenser structure and for the existing wet cooling towers each use half of the total mass flow rate of the recirculating cooling water. Furthermore, the temperature of the recirculation water leaving the 
steam condenser is indicated, as well as the temperature of the water flow exiting the conventional cooling tower.

The results for each of the hybrid systems are given in Table 3. The modular nature of the dry condenser/cooling towers are reflected by the identical hydrodynamic and thermal characteristics of the hybrid systems and their component systems, the DDTSC and IDTCT. Since calculation of the HPDC thermal resistances and overall dimensions is done using the same design inputs and solution method as the DDTSC, but the thermal load is halved, the dry condenser of the HPDC uses half the number of units, each with the same dimensions and pressure drop as that of the stand-alone DDTSC. Consequently, the thermal resistances associated with each thermosyphon are identical. The serial and parallel cooling towers (HSCT and HPCT, respectively) also involve individual thermosyphons and units of the same dimensions, flow behavior and heat transfer as the basic IDTCT design. However, both the HSCT and HPCT use half the number of units and half the number of thermosyphons than that of the IDTCT.

Due to the use of a conventional wet cooling tower in each hybrid system, there is additional pump work required for the flow of recirculation water, which is considered to be the amount of power required to move the total mass flow rate of cooling water between the cooling tower exit and the steam condenser cold-side inlet. However, the water loss for each hybrid system (157.5 $\mathrm{kg} / \mathrm{s}$ ) is half that predicted for a conventional system reliant solely on a wet cooling tower.

The hybrid parallel condenser (HPDC) requires a recirculation pump power of $0.754 \mathrm{MW}_{\mathrm{e}}$, with an increased overall effectiveness and coefficient of performance of 0.71 and 218 , respectively. Of particular importance is the cost per $\mathrm{kW}_{\text {th }}$ of the HPDC concept. Using the published costs of wet components as outlined by Tsou et al. (2013), the predicted cost per kW of thermal energy transferred was $\$ 23$, lower than the $\$ 31$ for the dry condenser designed for the entire thermal load of $730 \mathrm{MW}_{\text {th }}$ (Concept 1, DDTSC). This relatively minor difference in cost indicates that a dry condenser designed to dissipate the entire waste heat load will be more cost effective over time, due to the savings associated with minimizing water loss.

The hybrid series cooling tower (HSCT) provides the total $730 \mathrm{MW}_{\text {th }}$ cooling required with half the mass flow rate of the recirculation water as the IDTCT system. Correspondingly, the added pump work due to the conventional recirculation fluid flow was the same as for the hybrid parallel condensers, at $0.754 \mathrm{MW}_{\mathrm{e}}$, and with the associated water loss. An encouraging result of the system design is the significant increase to the coefficient of performance (292) compared to the original IDTCT (206). The cooling fan power is reduced by half for the HSCT, though there is the added pump power for the wet cooling tower. As a result, the total parasitic power of the serial dry and wet cooling towers is less, 2.49 $\mathrm{MW}_{\mathrm{e}}$ compared to 3.52 $\mathrm{MW}_{\mathrm{e}}$. However, there is a corresponding decrease in effectiveness (0.53). It is worth noting that the cost per $\mathrm{kW}_{\text {th }}$ of the HSCT is predicted to be $\$ 34$, which exceeds the design goals presented in Table 1 . 
The dry cooling tower of the hybrid parallel cooling tower (HPCT) concept is identically sized to that of the cooling towers in series (HSCT). However, the total mass flow rate of recirculation water is the same as the full amount required for the original IDTCT concept. The dry cooling tower receives half of the total mass flow rate of water to reject $365 \mathrm{MW}_{\text {th }}$, while the wet cooling tower is responsible for the remaining cooling load. This arrangement results in the same water loss as the other hybrid configurations, though with higher pumping power required. As expected, the pump power associated with the recirculation loop is double $\left(1.60 \mathrm{MWe}_{\mathrm{e}}\right)$ that of the serial cooling towers, which is again reflected in the reduced coefficient of performance of 218. The effectiveness of the parallel arrangement is 0.53 , which is the same as that for the serial towers. The major benefit of the parallel cooling towers is that total cooling of $730 \mathrm{MW}_{\text {th }}$ may be achieved at higher ambient temperature. It can be seen that the temperature of the hot flow leaving the conventional wet cooling tower is $36^{\circ} \mathrm{C}$, which is higher than the temperature of the source water, at approximately $21^{\circ} \mathrm{C}$ specified by Tsou et al. (2013), and higher than the temperature used for the HPDC and $\mathrm{HSCT}, 25^{\circ} \mathrm{C}$.

The fundamental dry systems (DDTSC and IDTCT) are briefly compared to existing systems, both wet and dry, for further proof of feasibility. Table 4 is included to directly quantify the benefits of the DDTSC and IDTCT over that of a conventional wet cooling tower for a $500 \mathrm{MW}$ e power plant, in terms of cooling efficiency and water savings. It should be noted that the cooling efficiency of both proposed systems are lower than that of the wet cooled plant, which is to be expected. However, when considering the overall efficiency, the significant water savings provided by the dry designs must be included. Using the average yearly water consumption values of a $500 \mathrm{MW}_{\mathrm{e}}$ power plant in California, as presented by Maulbetsch and DiFilippo (2006) and the cost of water provided by the City of San Diego Public Utilities Department (2016) the reduction in water usage can be quantified by examining the expected payback period. The previously calculated material cost of both designs is scaled by a cost factor of 2, to account for manufacturing, installation, labor, and other expenses related to the total capital cost. Including the cost scaling factor, the payback period is calculated to be 8.19 and 14.16 years for the DDTSC and IDTSCT, respectively. Even at the final adjusted cooling system costs, the proposed dry cooling solutions are still lower than the M\$90 total for a dry condenser of the same heat load described by Tsou et al. (2013).

\subsection{Parametric Simulations}

A parametric study was conducted for the DDTSC and IDTCT concepts to better illustrate the effects of changes to a number of design parameters. The parametric study did not include the hybrid concepts because of their reliance on the first two concepts, the DDTSC and IDTCT. The outer diameter, evaporator length, condenser length, and total air mass flow rate were varied by $+/-10 \%$ from the baseline case presented in Table 2 for both systems. In addition, the effect 
of modifications to the length of one unit of the DDTSC was examined, while the input water velocity was varied for the IDTCT.

The effect of each parameter on the DDTSC design is comprehensively summarized in Figure 12. At its most fundamental level, the design of a proposed dry condenser can be developed and altered based on the overall trends of the data. For example, it can be seen that increasing the length of a single unit lowers the effectiveness (Figure 12a) while simultaneously decreasing the air-side pressure drop (increasing the corresponding coefficient of performance (Figure 12b)). The same inverse relationship between effectiveness and coefficient of performance can be observed for changes in the evaporator section length of each thermosyphon.

The price per $\mathrm{kW}_{\text {th }}$ (Figure 12c) and the number of thermosyphons (Figure 12d) are included to illustrate the feasibility of the design and overall size of the system. Only the condenser length was noted to have an inverse relationship between cost and the number of thermosyphons. An increased condenser length resulted in a greater heat transfer rate from a single thermosyphon, and thus fewer thermosyphons were necessary to provide the cooling load.

The total parasitic power required to drive the cold-side fans of the DDTSC is included in Figure 12e, and the heat transfer to one module of the system is shown in Figure $12 \mathrm{f}$. Both the parasitic power and the heat transfer in a single module are inversely related to the coefficient of performance (Figure 12b).

The sensitivity of pertinent parameters to the inputs are evident in Figure 12a-d for the design of the DDTSC. From each figure, the most critical and least impactful parameter can be ascertained. For example, increasing the condenser length, $L_{c}$, causes the largest increase in cost

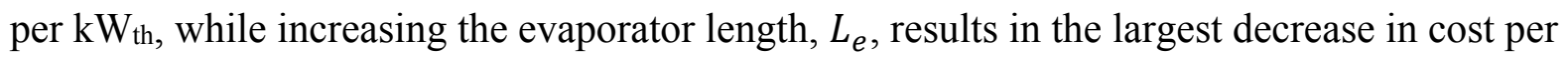
$\mathrm{kW}_{\text {th }}$ (Figure 12c).

Similar parametric predictions are presented for the IDTCT in Figure 13. The effectiveness, coefficient of performance, cost per $\mathrm{kW}_{\mathrm{th}}$, number of thermosyphons, total power, and heat rate of one module is given in Figure 13a-f.

Similar trends can be observed for the cooling tower (IDTCT) as for the condenser (DDTSC). The effect of each parameter is isolated and displayed in Figure 13, with several major observable differences. As previously described, the velocity of the hot water at the inlet, $U_{h o t, i}$, is an IDTCT-specific parameter. Therefore, the effect of changes to this parameter are included, instead of variations on the length, $L$, of a single unit.

Most notable is the peak effectiveness values that are obtained by decreasing the velocity of the hot water flow and the evaporator length (Figure 13a). Because the effectiveness and coefficient of performance are maximized, with a lower cost of the system, it is expected that the performance of the IDTCT is not yet optimal, and that a decreased hot flow velocity and evaporator section length may result in better performance. 
An important difference in the trends observed for the two different dry cooling concepts is the effect of the thermosyphon outer diameter. For the IDTCT, variation of the outer diameter of the themosyphons results in much greater change to the coefficient of performance (Figure 13b) than predicted for the DDTSC. This is because the latent heat transfer external to the evaporator section of a DDTSC module is modeled as condensation on a vertical flat plate. As a result, the length describing the heat transfer is that of the thermosyphon evaporator (Eq. 1), while the correlation used for the transfer of sensible heat to the finned tubes of the IDTCT uses the outer diameter of the thermosyphon as the characteristic length (Eq. 3). Correspondingly, the change in coefficient of performance due to the variation of the outer diameter by $10 \%$ is more than 3 times as large as for the IDTCT concept.

Variation of the water velocity had a larger effect on the coefficient of performance and total parasitic power (Figure 13b and Figure 13e, respectively) for the IDTCT than changes to the length of one unit for the DDTSC (Figure 12b and Figure 12e, respectively), relative to all other parameters. For the direct condenser, an increased evaporator length of one module most significantly increased the system's coefficient of performance. However, for the IDTCT, increased water velocity, $U_{h o t, i}$, was responsible for the largest decrease in coefficient of performance.

\section{Conclusion}

The performance in terms of cost, parasitic power requirements (coefficient of performance), and effectiveness, are presented for five water-saving heat exchanger concepts for application to thermoelectric power generation. All of the designs utilize the enhanced thermal conductivity and low temperature drop made possible by integration of closed two-phase thermosyphons. The first concept, a direct dry condenser (DDTSC) acts in place of the traditional wet condenser of a thermoelectric generation station. Instead of rejecting heat to a separate flow of water, to be redirected to a cooling tower, the thermal energy transfer required for condensation of the turbine exhaust steam is provided by cooling ambient air. The second concept, an indirect dry cooling tower (IDTCT) uses sensible energy transfer to the integrated thermosyphons, and provides a path of low thermal resistance for heat transfer to cool ambient air, without the evaporative mass losses of conventional cooling towers. The following three hybrid designs focus on the effective arrangement of the dry condenser and dry cooling tower, along with pre-existing wet cooling components. The first hybrid (HPDC) design uses a parallel flow arrangement to the dry condenser, as well as to the existing wet steam condenser. The following two hybrid systems (the HSCT and HPCT) involve series and parallel placements of a dry cooling tower, respectively. 
The proposed direct steam condenser is capable of a predicted effectiveness, coefficient of performance, and cost per $\mathrm{kW}_{\text {th }}$ of $0.55,376$, and $\$ 31 / \mathrm{kW}_{\mathrm{th}}$, respectively. The dry indirect cooling tower is predicted to have an effectiveness 0.77 , coefficient of performance of 206, and cost per $\mathrm{kW}_{\text {th }}$ of $\$ 54 / \mathrm{kW}_{\text {th. }}$. Each value is near to, or exceeds the federally proposed standards for dry cooling of thermoelectric plants, thus proving the feasibility of each concept.

The hybrid arrangements further demonstrate the utility of dry cooling using closed twophase thermosyphons to reduce water loss. Each hybrid design may be used along with the preexisting wet cooling components of a typical thermoelectric power plant, which is ideal for retrofit applications. The hybrid parallel condensers achieved a high coefficient of performance and effectiveness of 424 and 0.71 , respectively. More notably, the cost of the hybrid dry condenser and estimated wet cooling cost was similar $(\$ 23 / \mathrm{kW}$ th) to the overall cost of a dry condenser designed to handle the entire cooling load $\left(\$ 31 / \mathrm{kW}_{\text {th }}\right)$. The serial and parallel cooling towers attained a coefficient of performance of 292 and 218, respectively, and both had an effectiveness of 0.53 , at a cooling cost of $\$ 34 / \mathrm{kW}_{\text {th }}$.

Furthermore, a parametric study of the dry condenser and dry cooling tower concepts is presented for improved design analysis, and to better illustrate the effects of each design parameter on system size, cost, and performance. The two innovative, dry cooling designs investigated are but two conservation solutions presented with water conservation in mind.

\section{Acknowledgement}

This material is based upon work supported by the National Science Foundation under Grant Nos. 1435233 (University of Connecticut) and 1435131 (University of Kansas). 


\section{References}

T.L. Bergman, A.S. Lavine, F.P. Incropera and D.P. Dewitt, 2011, Fundamentals of Heat and Mass Transfer, Wiley, Ed. 7, ISBN: 9780470501979.

C.J. Brigida and W.J. Bow, 1983, “Wet/Dry Steam Condenser,” U.S. Patent, No. 4,381,817.

California Energy Commission, 2013, “2013 Integrated Energy Policy Report,” CEC-100-2013001-CMF. http://www.energy.ca.gov/2013publications/CEC-100-2013-001/CEC-100-2013001-CMF.pdf

City of San Diego Public Utilities Department, 2016, "Water Rates," https://www.sandiego.gov/water/rates/rates

A. Faghri, 1995, Heat Pipe Science and Technology, Taylor and Francis Group, Ed. 1, ISBN: 978-1560323839.

A. Faghri and Y. Zhang, 2006, Transport Phenomena in Multiphase Systems, Elsevier, Ed. ISBN: 978-0-12-370610-2.

A. Faghri, Y. Zhang and J.R. Howell, 2010, Advanced Heat and Mass Transfer, Global Digital Press, Ed. 1, ISBN: 978-0-98422760-0-4.

A. Faghri, 2014, "Heat Pipes: Review, Opportunities and Challenges," Frontiers in Heat Pipes, Vol. 5, doi: 10.5098/fhp.5.1.

Federal Water Pollution Control Act, 2011, Title 33 - Navigation and Navigable Waters, Chapter 26 - Water Pollution Prevention and Control.

http://www.waterboards.ca.gov/laws_regulations/docs/fedwaterpollutioncontrolact.pdf

W.H. Fisher, Jr. and B.M. Barnet, 1983, “Wet/Dry Steam Condenser,” U.S. Patent No. $4,379,485$.

M. Gao, L. Zhang, N. Wang, Y. Shi and F. Sun, 2016, "Influence of Non-uniform Layout Fillings on Thermal Performance for Wet Cooling Tower," Applied Thermal Engineering, Vol. 93, pp. 549-555.

Z. Ge, X. Du, L. Yang, Y. Yang, Y. Li and Y. Jin, 2011, "Performance Monitoring of Direct Aircooled Power Generating Unit with Infrared Thermography," Applied Thermal Engineering, Vol. 31, Issue 4, pp. 418-424.

F.O. Goodman and H.Y. Wachman, 1967, "Formula for Thermal Accommodation Coefficients," Journal of Chemical Physics, Vol. 46, doi:10.1063/1.1841046. 
E.D. Grimison, 1937, "Correlation and Utilization of New Data on Flow Resistance and Heat Transfer for Cross Flow of Gases Over Tube Banks." Transactions of the ASME, Vol. 59, No. 7, pp. 583-594.

R. Howitt, J. Medellin-Azuara, D. MacEwan, J. Lund and D. Sumner, 2014, "Economic Analysis of the 2014 Drought for California Agriculture," Center for Watershed Sciences, University of California, Davis, California. http://watershed.ucdavis.edu

S.P. Kearney and A.M. Jacobi, 1995, "Local and Average Heat Transfer and Pressure Drop Characteristics of Annularly Finned Tube Heat Exchangers," ACRC Report No. 69. http://hdl.handle.net/2142/10990

B.H. Kim and C.J. Kim, 1995, "Design Optimization for the Performance Enhancement of Large Scale Thermosyphons," KSME Journal, Vol. 9, No. 3, pp. 286-297, doi: 10.1007/BF02953627

D.G. Kröger, 2004, Air-cooled Heat Exchangers and Cooling Towers, Vol. 1. PennWell Books, ISBN: 0878148965

G.R. Kudritskii, 1994, "Operation of Thermosyphons at Small Angles of Inclination to the Horizontal, Journal of Engineering Physics and Thermophysics, Vol. 67, Issue 3, pp. 914916, doi: 10.1007/BF00853019

L. Kunsagi and E.L. Daman, 1980, "Heat Exchange Apparatus Utilizing Thermal Siphon Pipes," U.S. Patent, No. 4,226,282.

C. Kutscher and D. Costenaro, 2002, "Assessment of Evaporative Cooling Enhancement Methods for Air-cooled Geothermal Power Plants," Transactions-Geothermal Resources Council, Reno, Nevada, pp. 775-780.

P. Liu, H. Duan and W. Zhao, 2009, "Numerical Investigation of Hot Air Recirculation of Aircooled Condensers at a Large Power Plant," Applied Thermal Engineering, Vol. 29, Issue 10, pp. 1927-1934.

J.S. Maulbetsch, 2012, "Water Conserving Cooling Systems - Air-cooled Condensers," ARPA-E Workshop, http://arpa-e.energy.gov/

J.S. Maulbetsch and M.N. DiFilippo, 2006, "Cost and Value of Water Use at Combined-cycle Power Plants,” California Energy Commission, PIER Energy-Related Environmental Research, Report No. CEC-500-2006-034, p. 7.

M.A. Maupin, J.F. Kenny, S.S. Hutson, J.K. Lovelace, N.L. Barber and K.S. Linsey, 2014, "Estimated Use of Water in the United States in 2010: U.S. Geological Survey," Circular No. 1405, http://dx.doi.org/10.3133/cir1405. 
MetalPrices.com, 2015, “Metal Index," Argus Media, http://www.metalprices.com/p/metal_index

H. Müeller-Steinhagen, 2000, Heat Exchanger Fouling: Mitigation and Cleaning Technologies, Institution of Chemical Engineers, Ed. 1, ISBN: 0852954360

S. Narayanan, 2010, "Cleaning System and Method for Air-cooled Condenser Bundles,” U.S. Patent, No. 12/408,471.

NVEnergy, 2014, "Higgins Fact Sheet," https://www.nvenergy.com/company/energytopics/images/Higgins_Fact Sheet.pdf

R.E. Putman and D. Jaresch, 2002, "The Cleaning of Air Cooled Condensers to Improve Performance,” ASME, International Joint Power Generation Conference, Phoenix, Arizona.

K.K. Robinson and D.E. Briggs, 1966, "Pressure Drop of Air Flowing Across Triangular Pitch Banks of Finned Tubes," Chemical Engineering Progress Symposium Series, Vol. 62, No. 64.

A.S. Robertson and E.C. Cady, 1980, "Development and Operational Testing of a Heat Pipe Dry Cooling Tower," ASME, Joint Power Conference, Phoenix, Arizona.

H. Shabgard, M.J. Allen, N. Sharifi, S.P. Benn, A. Faghri and T.L. Bergman, 2015, "Heat pipe Heat Exchangers and Heat Sinks: Opportunities, Challenges, Applications, Analysis, and State of the Art," International Journal of Heat and Mass Transfer, Vol. 89, pp. 138-158.

H. Shabgard, C.W. Robak, T.L. Bergman and A. Faghri, 2012, "Heat Transfer and Exergy Analysis of Cascaded Latent Heat Storage with Gravity-assisted Heat Pipes for Concentrating Solar Power Applications," Solar Energy, Vol. 86, Issue 3, pp. 816-830. http://dx.doi.org/10.1016/j.solener.2011.12.008

A.I. Strel'tsov, 1975, “Theoretical and Experimental Investigation of Optimum Filling for Heat Pipes” Heat Transfer-Sov. Res., Vol. 7, Issue 1, pp. 23-27.

J.L. Tsou, J. Maulbetsch and J. Shi, 2013, "Power Plant Cooling System Overview for Researchers and Technology Developers," Electric Power Research Institute, Report No. 3002001915.

H. Shabgard, T.L. Bergman, N. Sharifi and A. Faghri, 2010, "High Temperature Latent Heat Thermal Energy Storage Using Heat Pipes," International Journal of Heat and Mass Transfer, Vol. 53, Issues: 15-16, pp. 2979-2988.

doi:10.1016/j.ijheatmasstransfer.2010.03.035 
U.S. Department of Energy, 2014, "Advanced Research in Dry-Cooling (ARID)," Funding Opportunity No. DE-FOA-0001197, CFDA No. 81.135, Modification 3.

K. Warikoo, 2016, Xinjiang-China's Northwest Frontier, Routledge, ISBN: 9781138184916.

Y.M. Xuan, F. Xiao, N.F. Niu, X.Huang and S.W. Wang, 2012a, "Research and Application of Evaporative Cooling in China: A Review (I)-Research," Renewable and Sustainable Energy Reviews, Vol. 16, Issue 5, pp. 3535-3546.

Y.M. Xuan, F. Xiao, N.F. Niu, X.Huang and S.W. Wang, 2012b, "Research and Applications of Evaporative Cooling in China: A Review (II)-Systems and Equipment," Renewable and Sustainable Energy Reviews, Vol. 16, Issue 5, pp. 3523-3534.

G. Zhifu, H. Li, W. Zhang, Y. Li and J. Pang, 2005, "Wind Tunnel Simulation on Re-circulation of Air-cooled Condensers of a Power Plant," Journal of Wind Engineering and Industrial Aerodynamics, Vol. 93, Issue 6, pp. 509-520.

A. Žukauskas and R. Ulinskas, 1988, Heat Transfer in Tube Banks in Crossflow, Hemisphere Publishing, pp. 130-131, ISBN: 3-540-18865-7.

Z.J. Zuo and A. Faghri, 1998, "A Network Thermodynamic Analysis of the Heat Pipe," International Journal of Heat and Mass Transfer, Vol. 41, Issue. 11, pp. 1473-1484. doi:10.1016/S0017-9310(97)00220-2 


\section{List of Figures}

Figure 1: Concept 1 - Direct dry thermosyphon condenser (DDTSC). ............................................... 35

Figure 2: Concept 2 - Indirect dry thermosyphon cooling tower (IDTCT) . .......................................... 35

Figure 3: Concept 3 - Hybrid parallel direct condensers (HPDC). ....................................................... 36

Figure 4: Concept 4 - Hybrid series cooling towers (HSCT) ............................................................. 36

Figure 5: Concept 5 - Hybrid parallel cooling towers (HPCT) .......................................................... 37

Figure 6: A single thermosyphon and associated elements comprising a module for the DDTSC (no

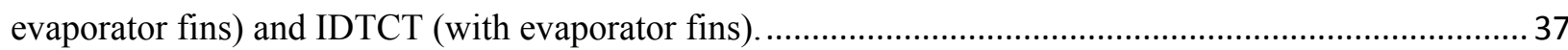

Figure 7: Staggered arrangement for one unit of a thermosyphon heat exchanger................................... 38

Figure 8: A single unit and associated elements in crossflow for either dry cooling systems..................38

Figure 9: Overall system representations of air flow through the DDTSC or IDTCT ( $\otimes$ denotes flow into

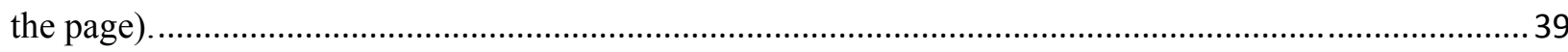

Figure 10: Operating conditions for Higgins dry condenser (Maulbetsch, 2012). ................................. 39

Figure 11: Thermal network for a single thermosyphon with external and internal resistances................40 Figure 12: DDTSC parametric variables: $i)$ Unit length, $L(-)$ ii) Thermosyphon outer diameter, Do ( -.•) iii) Evaporator length, Le (-), iv) Condenser length, $L c(-\mathbf{-})$, and $v$ ) Total air mass flow rate, mair ( $\Delta$ ) and their effect on $a$ ) Effectiveness, $b$ ) Coefficient of performance, $c$ ) Price of thermal energy transfer, $d$ ) Number of thermosyphons, $e$ ) Total parasitic power, and f) Heat transfer by one module on parametric variables: Each parameter value (at $0 \%$ scaling) is found in Table 2

Figure 13: IDTCT parametric variables: $i)$ Input water velocity, $U w(-)$ ii) Thermosyphon outer diameter, Do (••) iii) Evaporator length, Le (-) and iv) Condenser length, $L c(\boldsymbol{-}$-) v) Total air mass flow rate, mair ( $\boldsymbol{\Delta}$ ) and their effect on a) Effectiveness, b) Coefficient of performance, $c$ ) Price of thermal energy transfer, $d$ ) Number of thermosyphons, $e$ ) Total parasitic power, and $f$ ) Heat transfer by one module. Each parameter value (at $0 \%$ scaling) is found in Table 2 


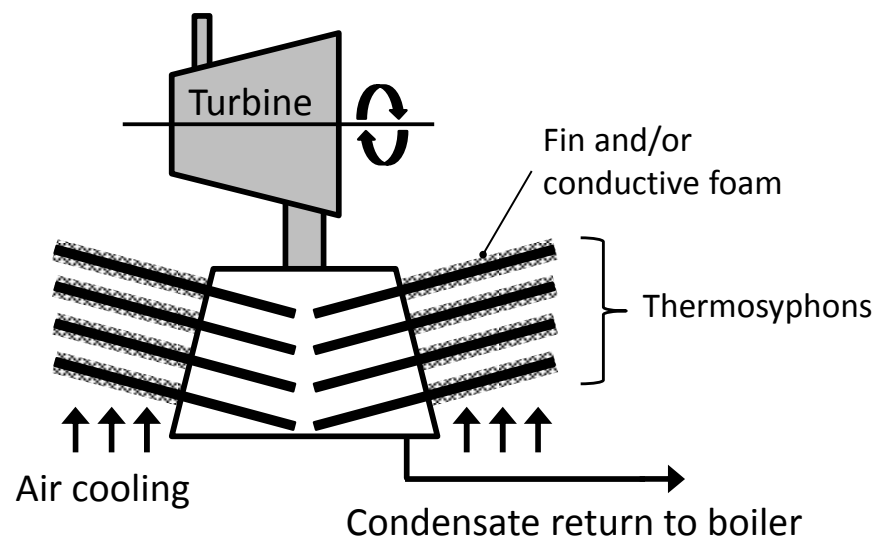

Figure 1: Concept 1 - Direct dry thermosyphon condenser (DDTSC).

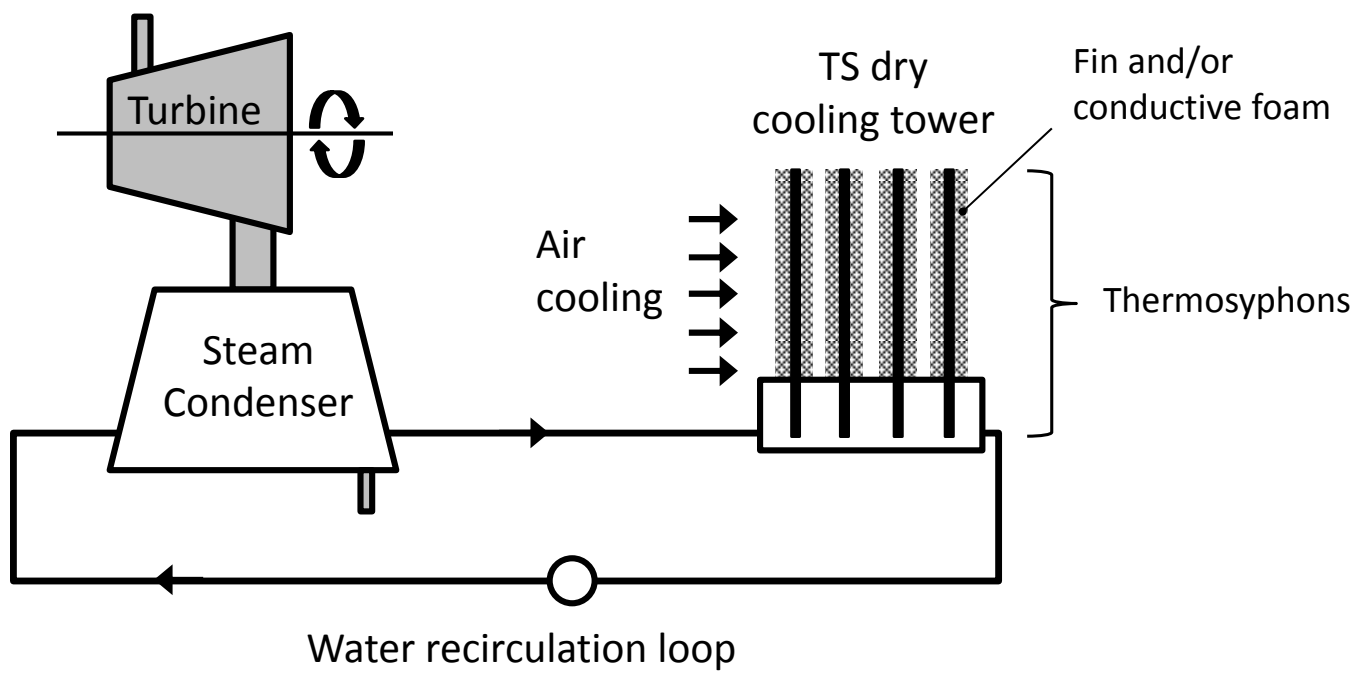

Figure 2: Concept 2 - Indirect dry thermosyphon cooling tower (IDTCT). 


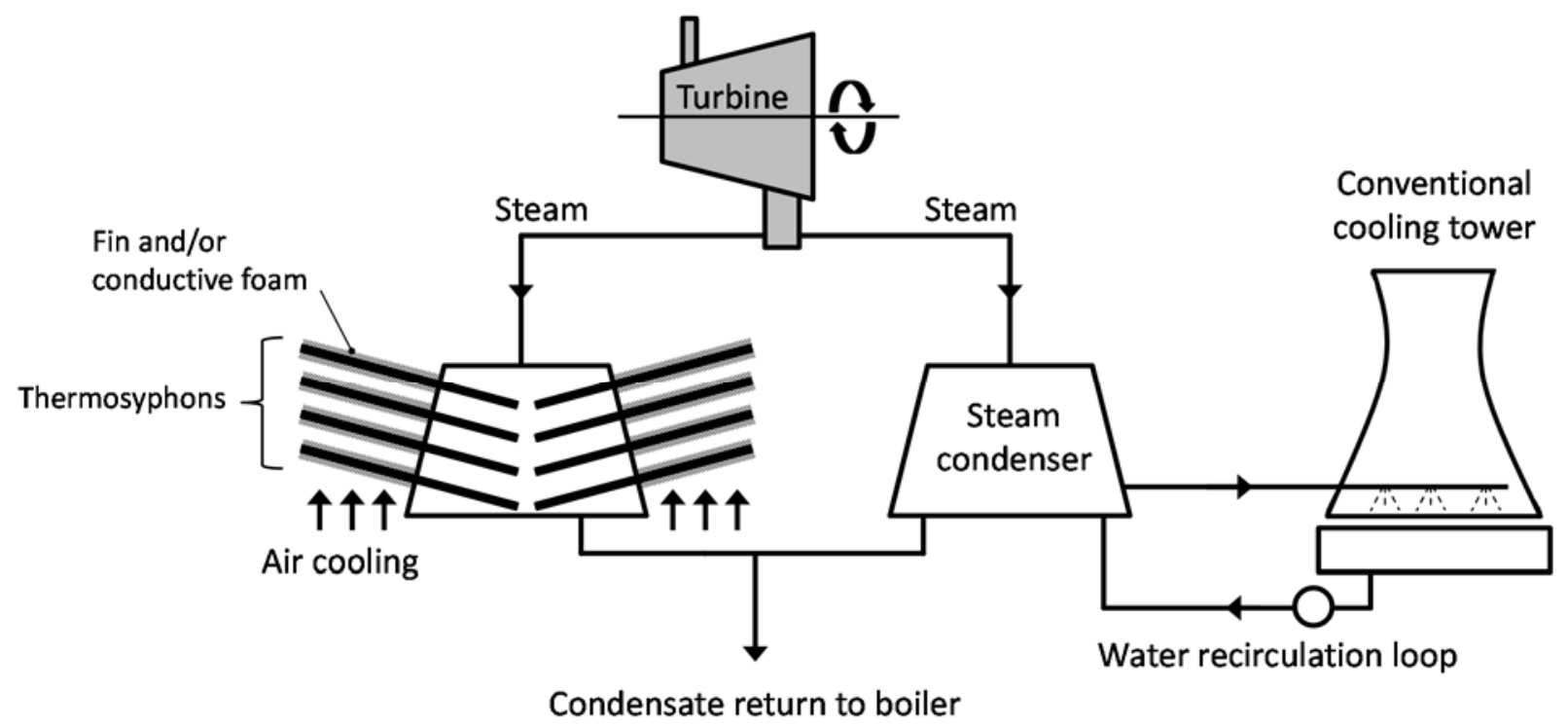

Figure 3: Concept 3 - Hybrid parallel direct condensers (HPDC).

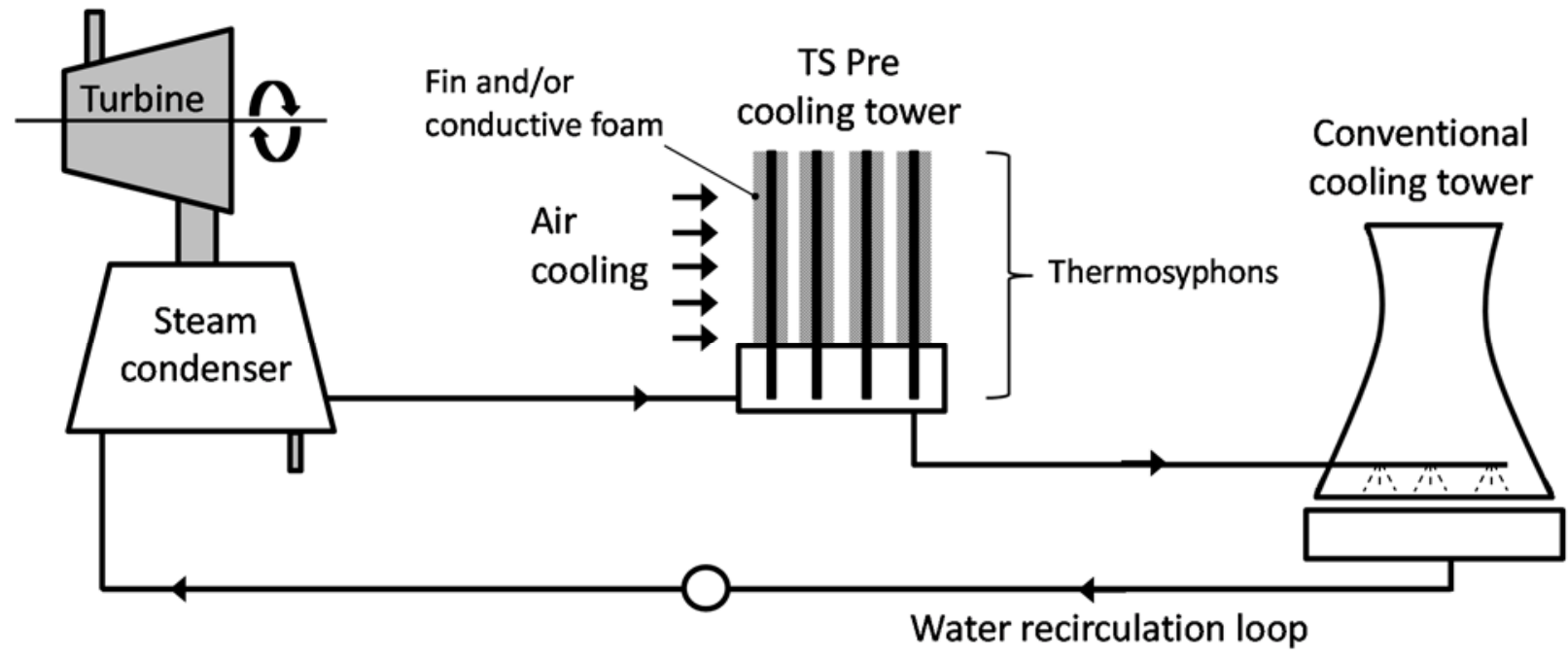

Figure 4: Concept 4 - Hybrid series cooling towers (HSCT). 


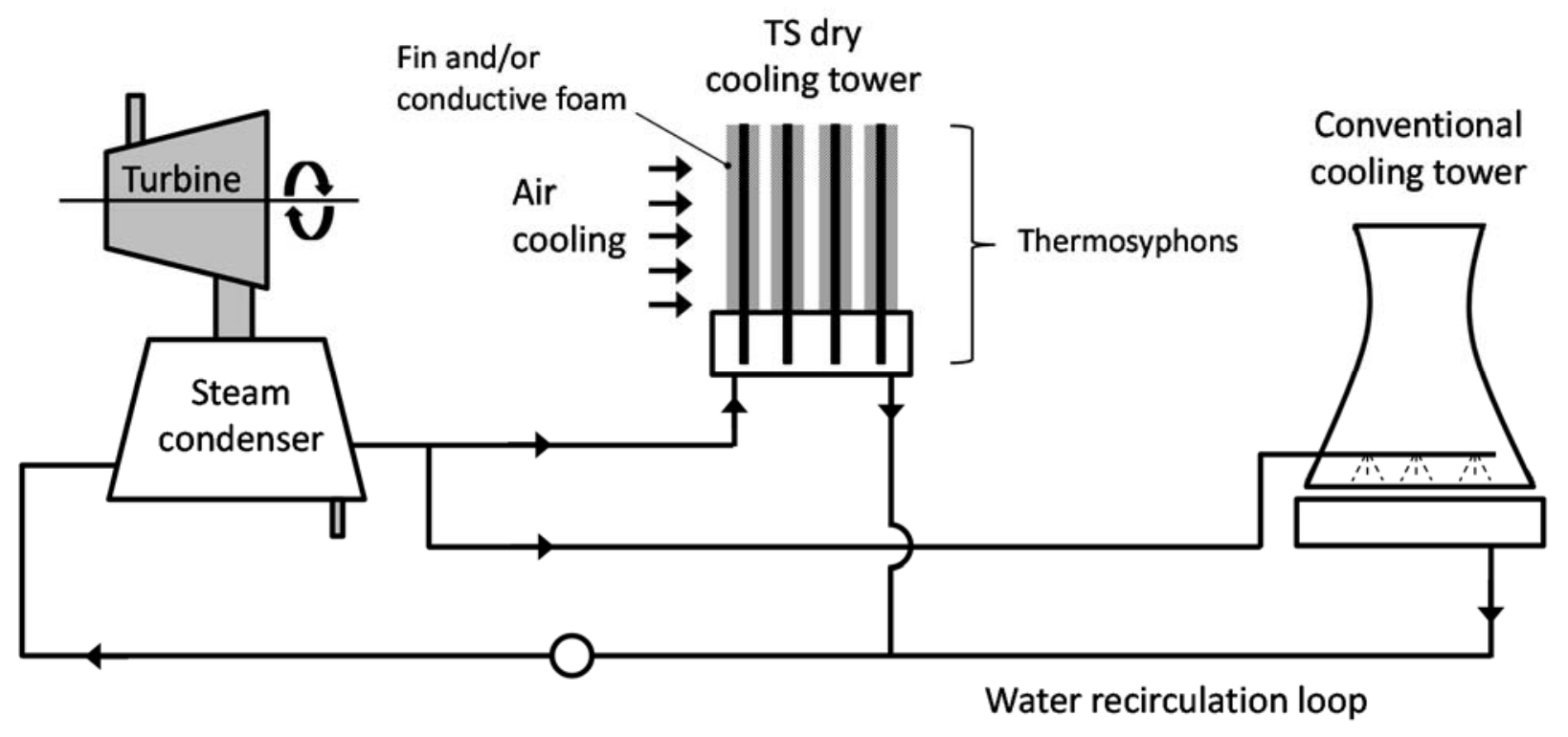

Figure 5: Concept 5 - Hybrid parallel cooling towers (HPCT).

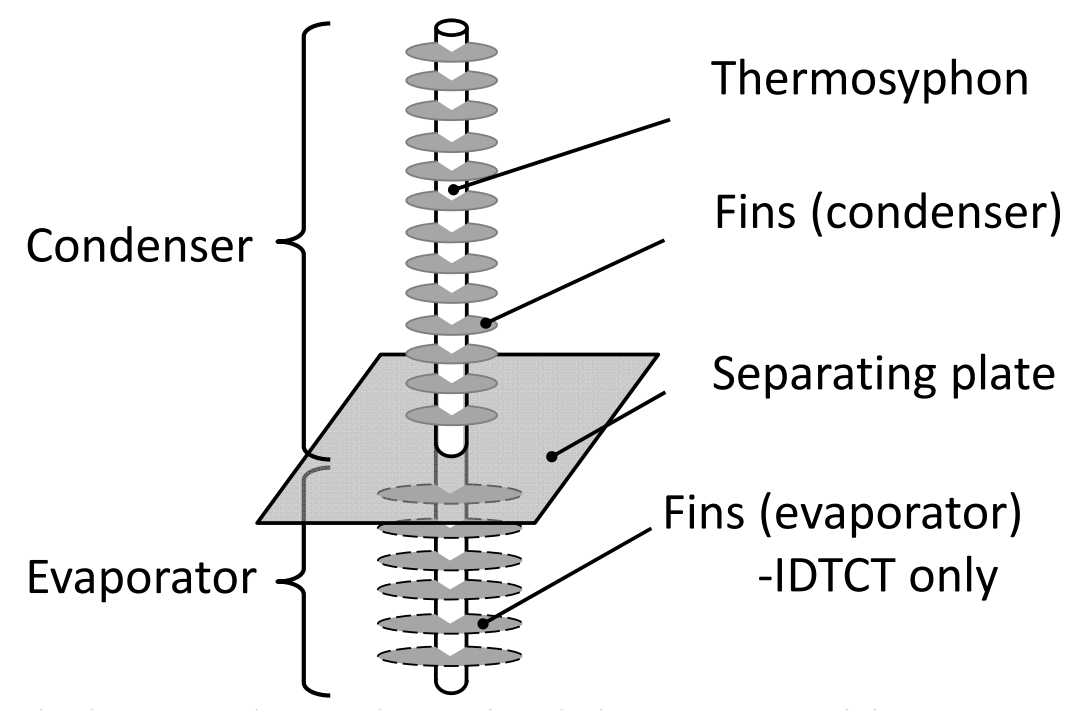

Figure 6: A single thermosyphon and associated elements comprising a module for the DDTSC (no evaporator fins) and IDTCT (with evaporator fins). 


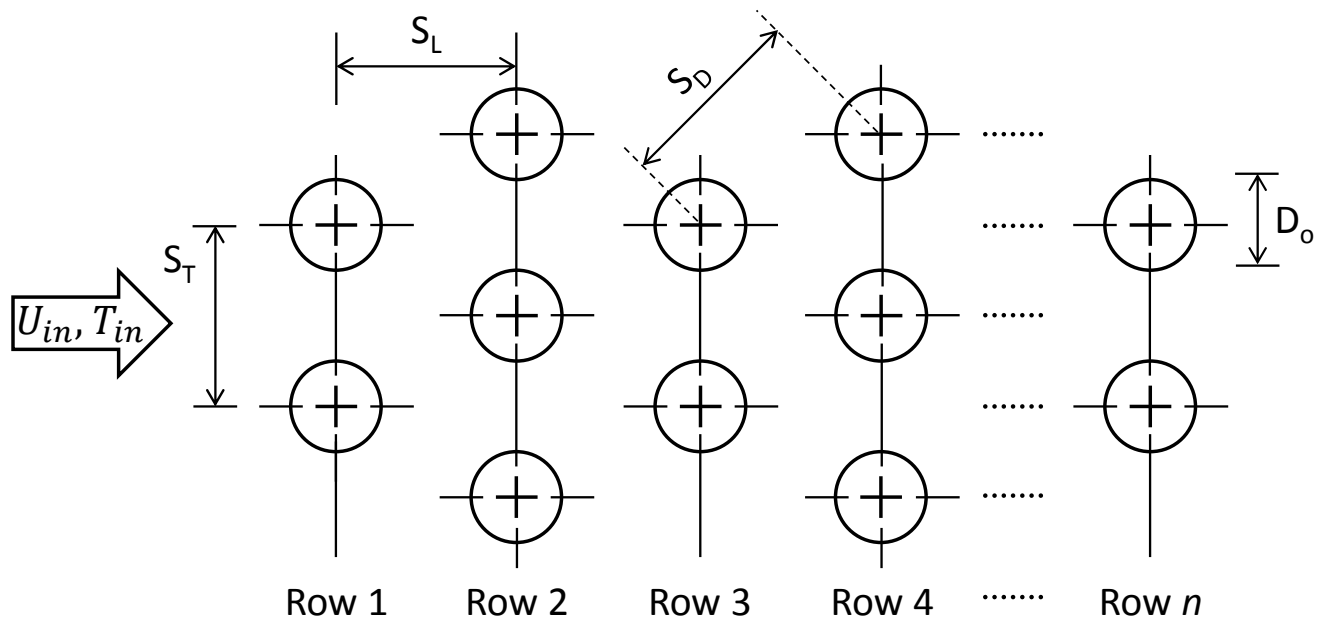

Figure 7: Staggered arrangement for one unit of a thermosyphon heat exchanger.

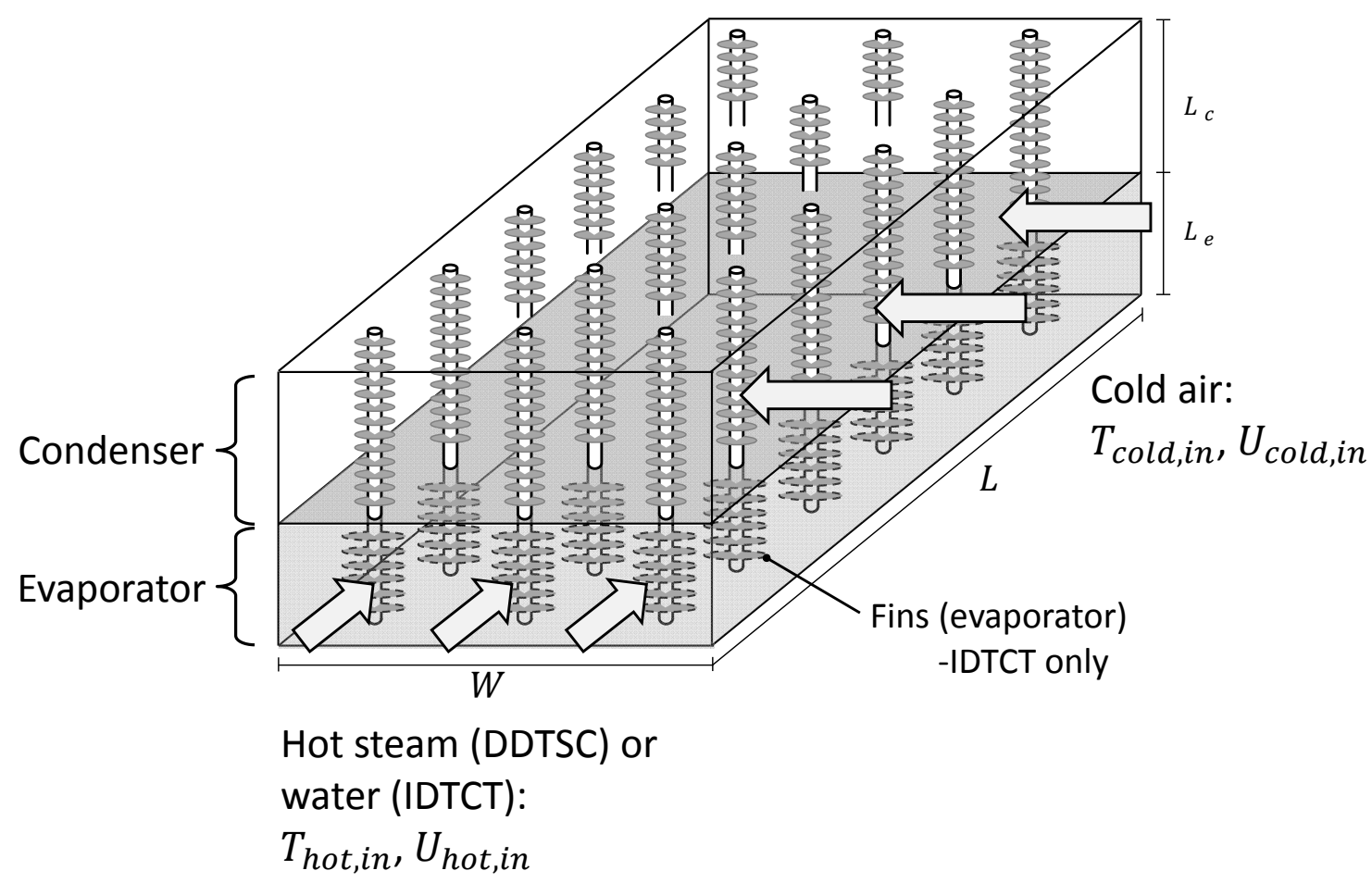

Figure 8: A single unit and associated elements in crossflow for either dry cooling systems. 


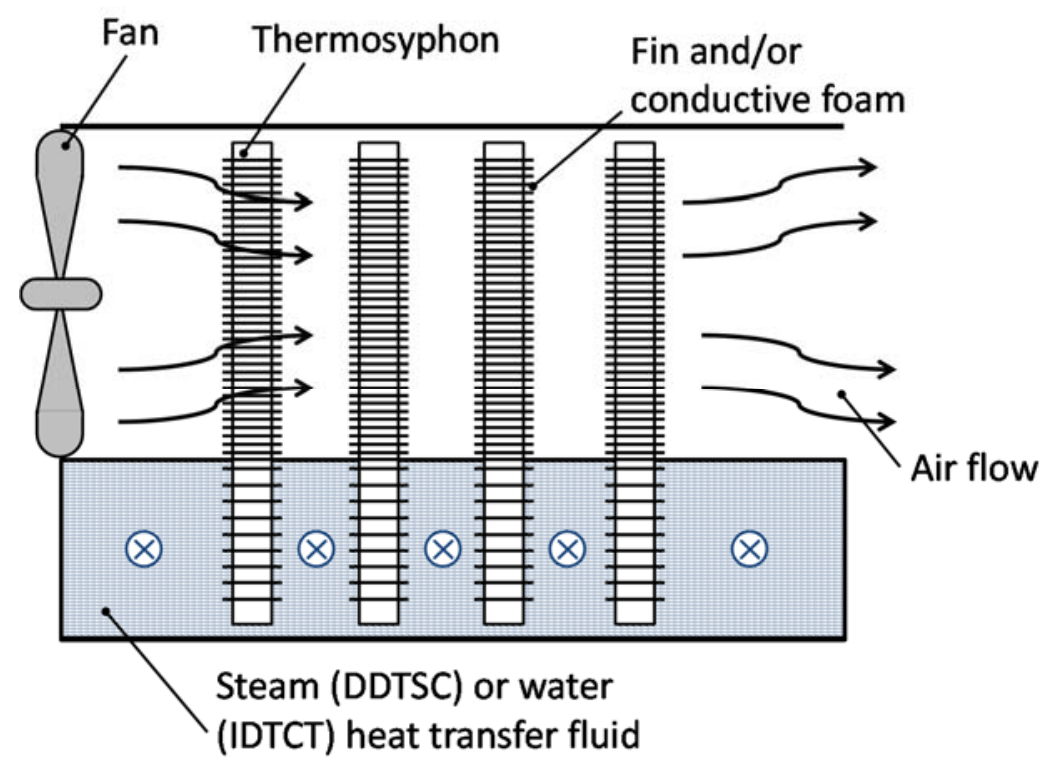

Figure 9: Overall system representations of air flow through the DDTSC or IDTCT $(\otimes$ denotes flow into the page).

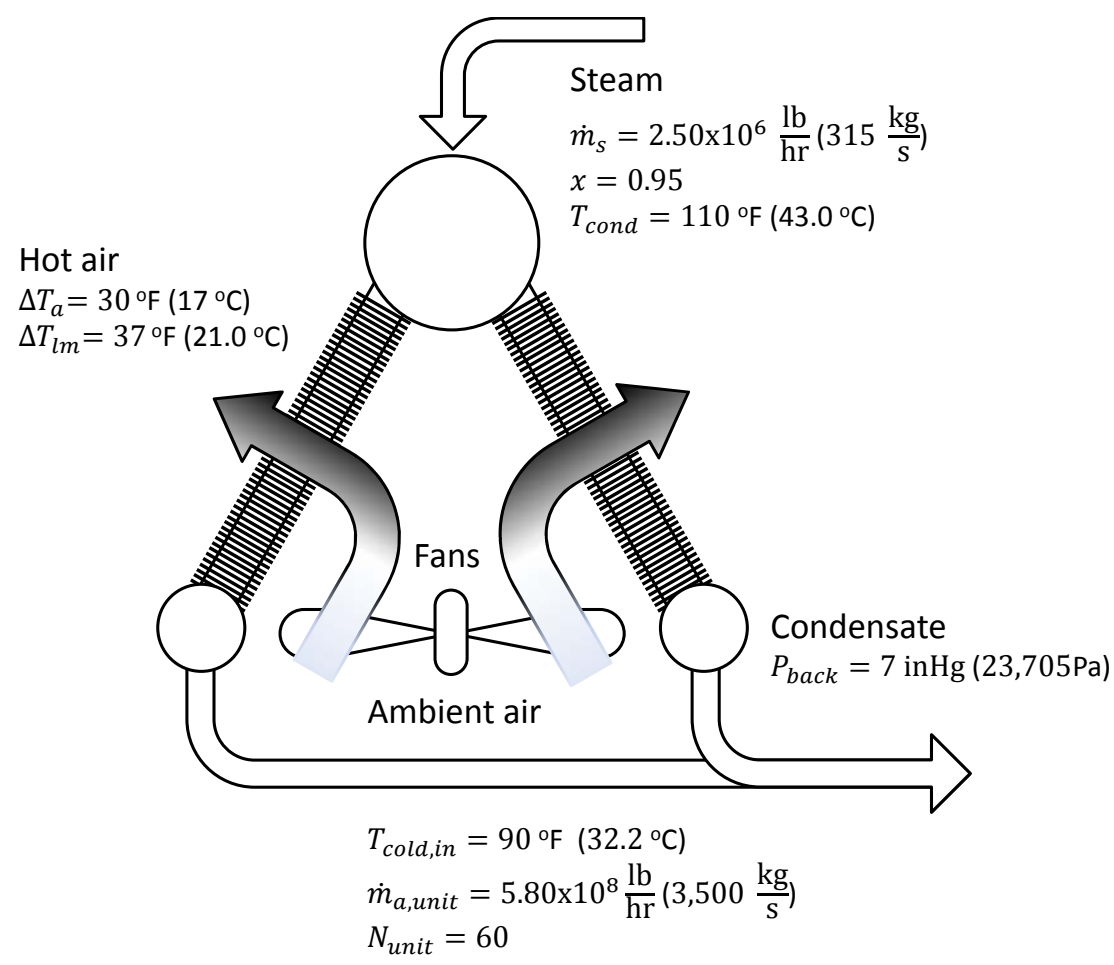

Figure 10: Operating conditions for Higgins dry condenser (Maulbetsch, 2012). 


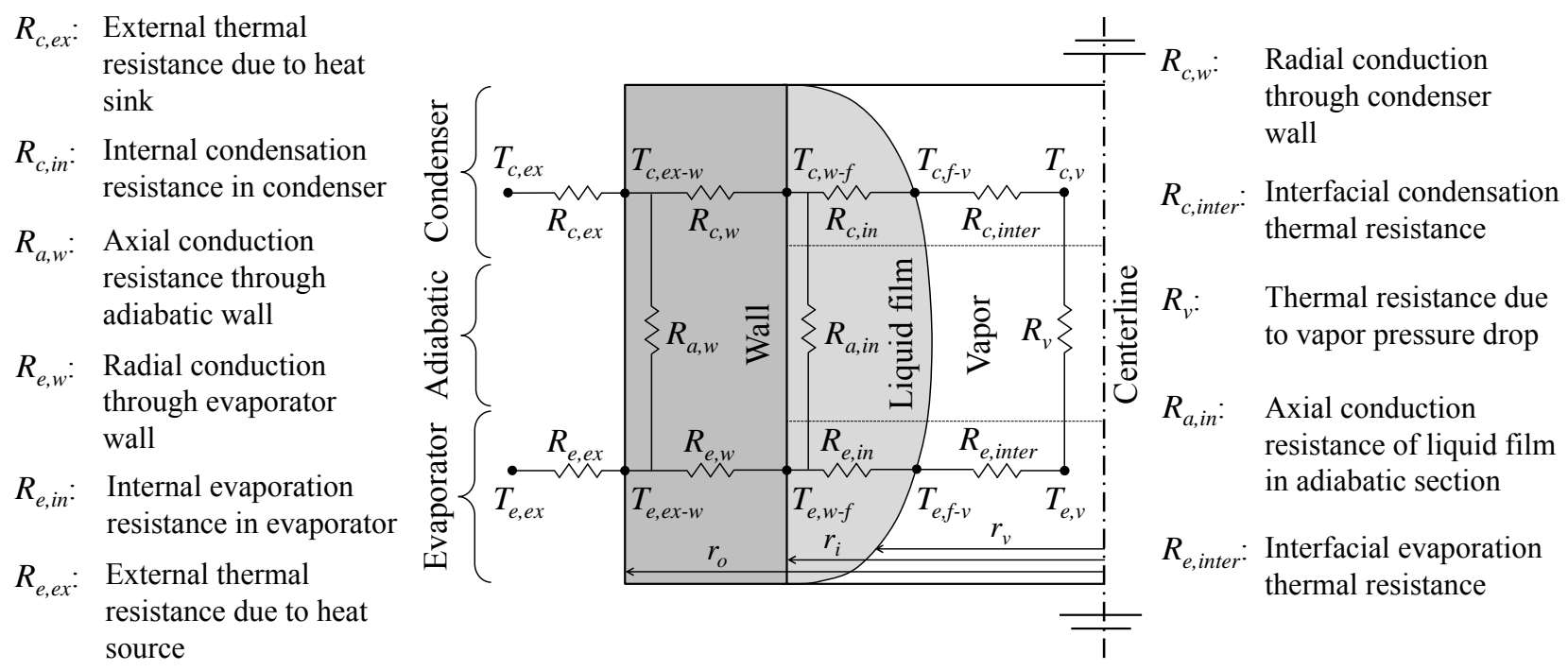

Figure 11: Thermal network for a single thermosyphon with external and internal resistances. 


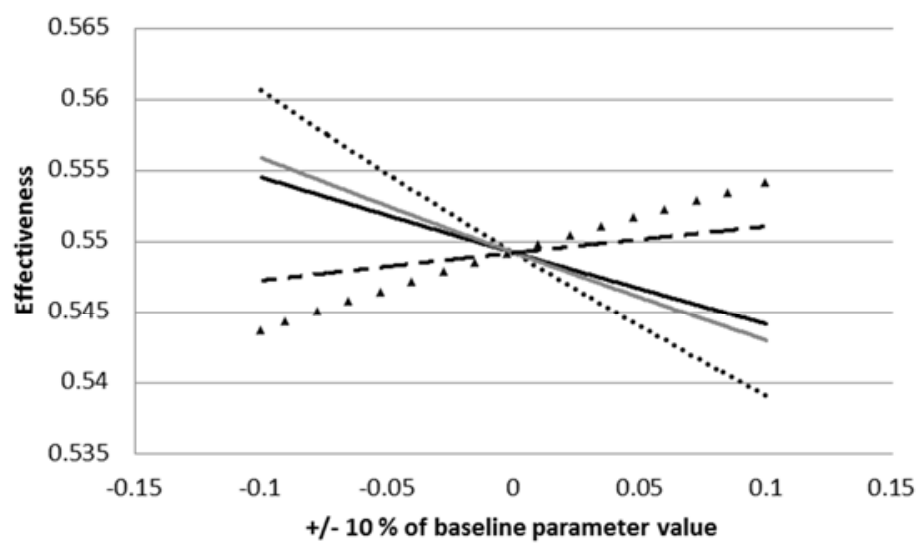

(a)

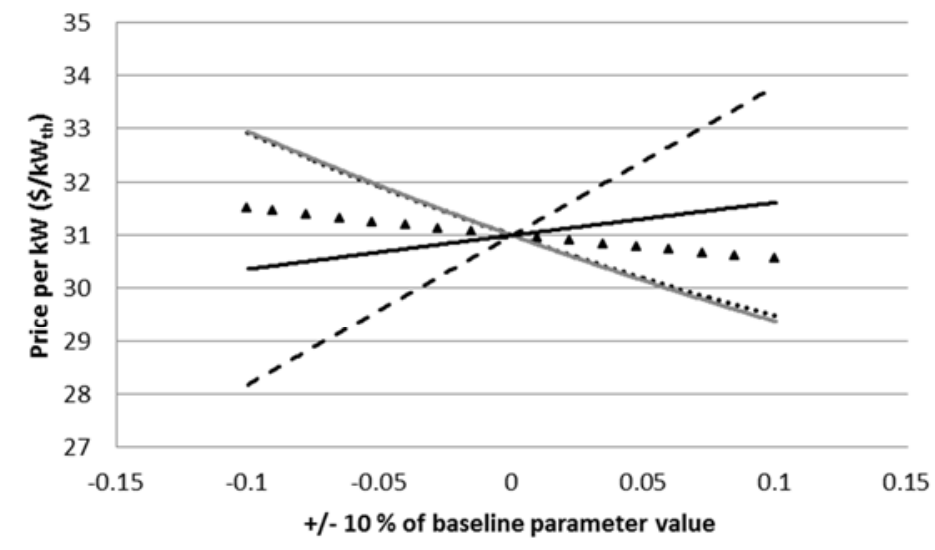

(c)

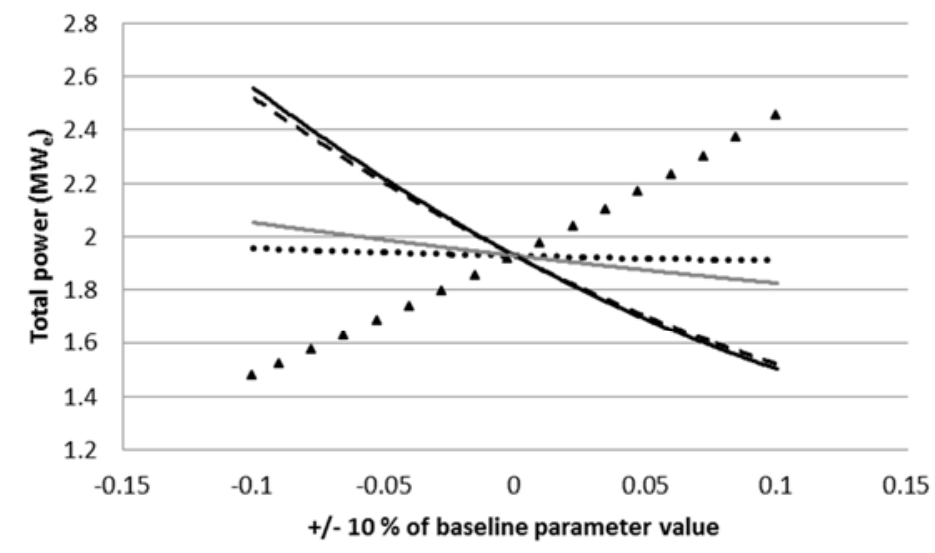

(e)

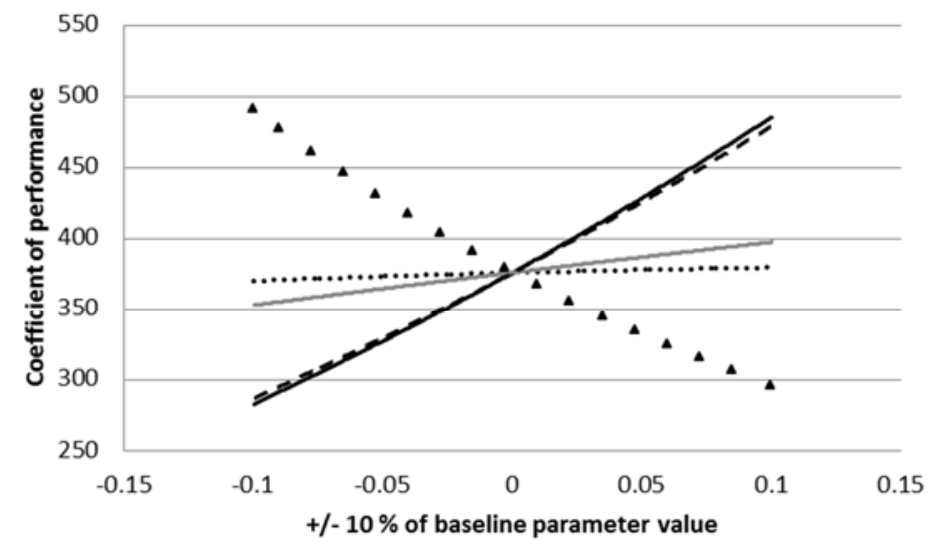

(b)

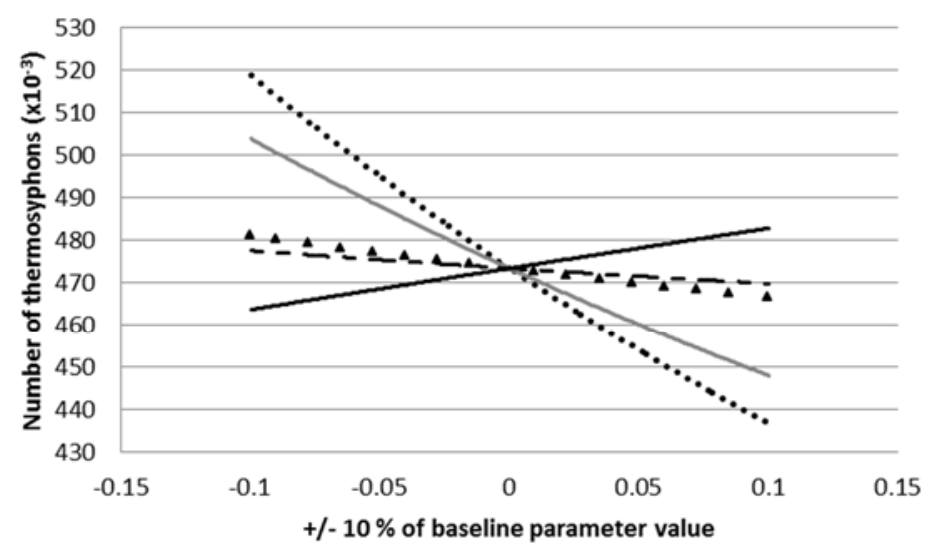

(d)

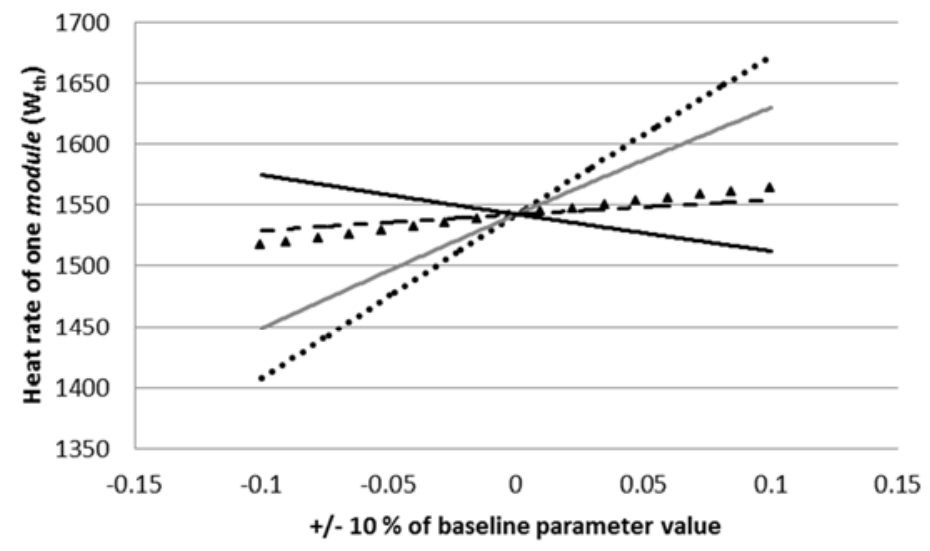

(f)

Figure 12: DDTSC parametric variables: i) Unit length, $\boldsymbol{L}(-)$ ii) Thermosyphon outer diameter, $\boldsymbol{d}_{\boldsymbol{o}}(\boldsymbol{\bullet})$ iii) Evaporator length, $\boldsymbol{L}_{\boldsymbol{e}}(-)$, iv) Condenser length, $\boldsymbol{L}_{\boldsymbol{c}}(\boldsymbol{-} \boldsymbol{-})$, and v) Total air mass flow rate, $\dot{\boldsymbol{m}}_{\text {air }}(\boldsymbol{\Delta})$ and their effect on $a$ ) Effectiveness, $b$ ) Coefficient of performance, $c$ ) Price of thermal energy transfer, $d$ ) Number of thermosyphons, e) Total parasitic power, and f) Heat transfer by one module on parametric variables: Each parameter value (at $0 \%$ scaling) is found in Table 2 . 


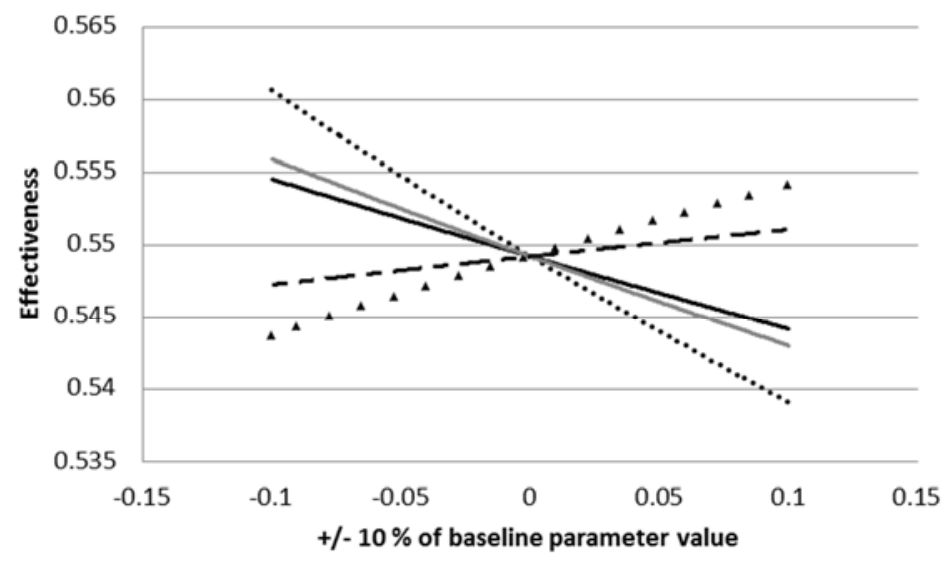

(a)

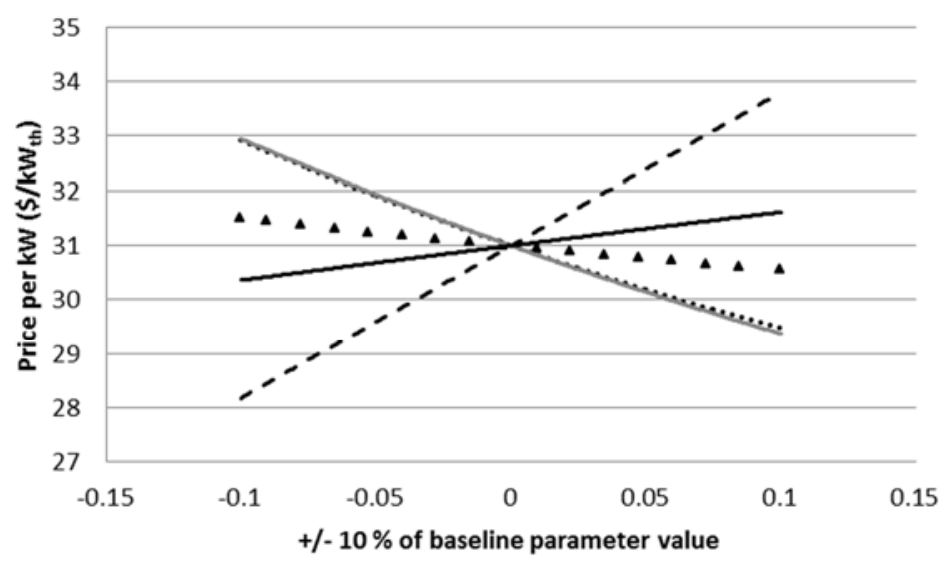

(c)

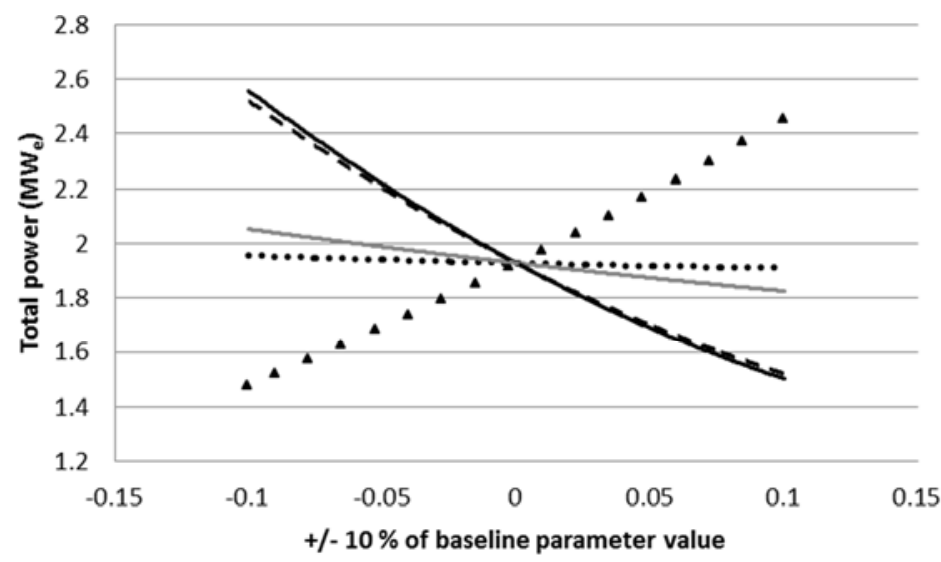

(e)

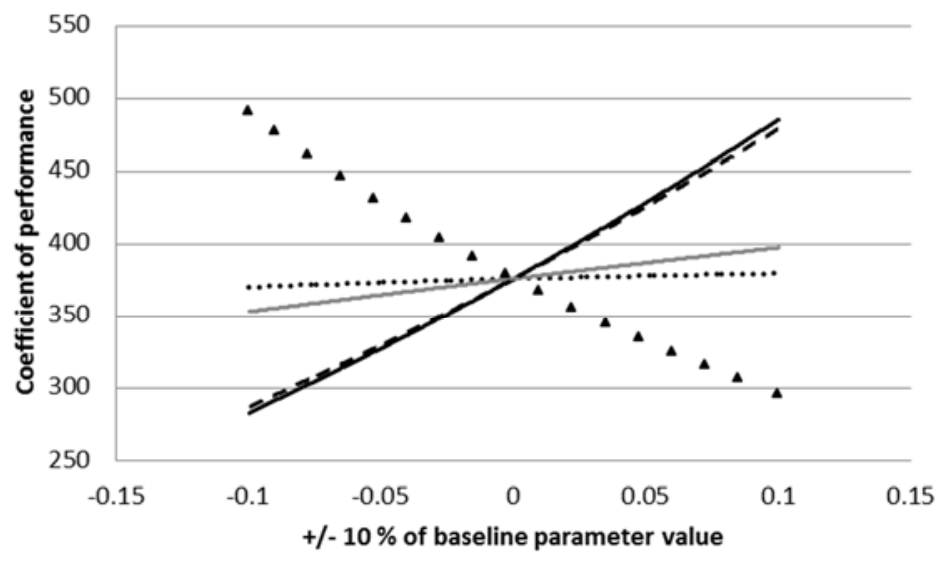

(b)

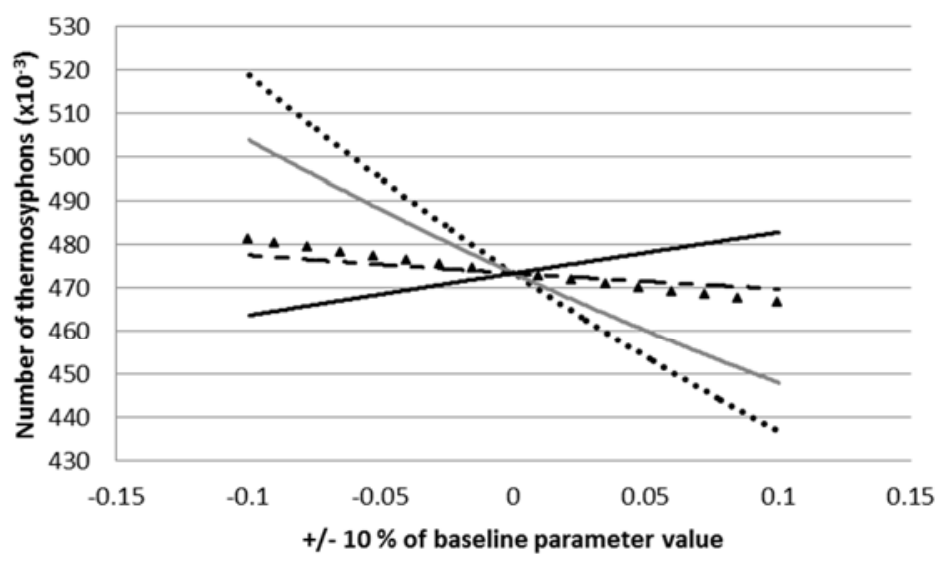

(d)

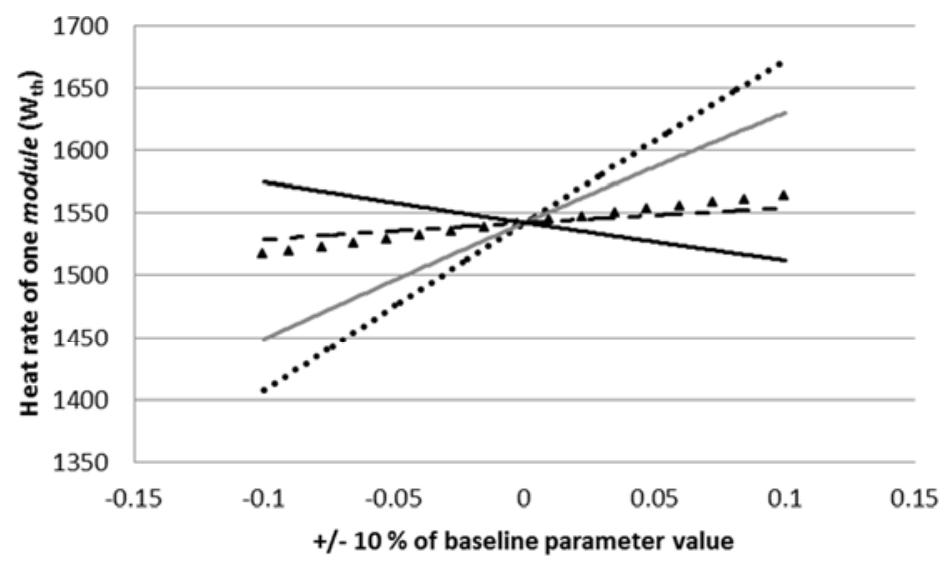

(f)

Figure 13: IDTCT parametric variables: i) Input water velocity, $\boldsymbol{U}_{\boldsymbol{h o t}, \boldsymbol{i}}(-)$ ii) Thermosyphon outer diameter, $\boldsymbol{d}_{\boldsymbol{o}}(\boldsymbol{\cdots})$ iii) Evaporator length, $\boldsymbol{L}_{\boldsymbol{e}}(-)$ and iv) Condenser length, $\boldsymbol{L}_{\boldsymbol{c}}(\boldsymbol{-}-\boldsymbol{-})$ ) Total air mass flow rate, $\boldsymbol{\boldsymbol { m }}_{\text {air }}$ $(\Delta)$ and their effect on $a$ ) Effectiveness, $b$ ) Coefficient of performance, $c$ ) Price of thermal energy transfer, $d$ ) Number of thermosyphons, $e$ ) Total parasitic power, and $f$ ) Heat transfer by one module. Each parameter value (at $0 \%$ scaling) is found in Table 2. 


\section{List of Tables}

Table 1: Design goals for non-metallic air-cooled heat exchangers (U.S. Department of Energy, 2014). 44

Table 2: DDTSC and IDTCT physical description, thermal characteristics, and performance.

Table 3: Hybrid concepts (HPDC, HSCT, HPCT) physical description, thermal characteristics, and performance. 46

Table 4: Cooling Efficiency and Estimated Payback Period Compared to Wet Cooling ..... 47 
Table 1: Design goals for non-metallic air-cooled heat exchangers (U.S. Department of Energy, 2014).

\begin{tabular}{|l|c|}
\hline \multicolumn{1}{|c|}{ Description } & Goal \\
\hline Heat exchanger coefficient of performance $\left(\mathrm{COP}_{H X}\right)$ & $\mathrm{COP}_{H X} \geq 200$ \\
\hline Heat exchanger effectiveness $(\varepsilon)$ & $\varepsilon>0.6$ \\
\hline Capital cost of heat exchanger & Cost $\leq \$ 50 / \mathrm{kW}_{\text {th }}$ \\
\hline
\end{tabular}


Table 2: DDTSC and IDTCT physical description, thermal characteristics, and performance.

\begin{tabular}{|c|c|c|c|c|c|}
\hline \multicolumn{3}{|c|}{ Inputs } & \multicolumn{3}{|c|}{ Outputs } \\
\hline System Parameters & DDTSC & IDTCT & Flow Dynamics & DDTSC & IDTCT \\
\hline Cooling load [MW $\mathrm{MW}_{\mathrm{th}}$ & 730 & 730 & Hot flow velocity [m/s] & 3.72 & N.A. \\
\hline Pump efficiency & 0.90 & 0.90 & Cold flow velocity [m/s] & 4.82 & 1.23 \\
\hline Fan efficiency & 0.90 & 0.90 & $\Delta$ Pair $[\mathrm{Pa}]$ & 5.45 & 1.99 \\
\hline Thermosyphon Specificiations & & & $\Delta \mathrm{Pe}, \mathrm{ex}[\mathrm{Pa}]$ & N.A. & $1.90 \mathrm{E} 5$ \\
\hline Wall material & S.S. AISI-304 & S.S. AISI-304 & Heat Transfer Coefficients [W/m² $\mathrm{K}]$ & & \\
\hline Outer diameter [m] & 0.025 & 0.125 & Internal liquid film (evap./cond.) & 6.08E3/8.56E3 & 9.20E3/1.53E4 \\
\hline Inner diameter [m] & 0.023 & 0.123 & External flow to TS (evap./cond.) & $6.97 \mathrm{E} 3 / 18.12$ & $517.33 / 8.50$ \\
\hline Length (evap./cond.) [m] & $0.50 / 6.0$ & $0.50 / 6.0$ & Thermal Resistance $\left[{ }^{\circ} \mathrm{C} / \mathrm{W}\right]$ & & \\
\hline Adiabatic length & 0 & 0 & Evaporator to hot flow, $R_{e, e x}$ & $3.7 \mathrm{E}-3$ & $5.65 \mathrm{E}-4$ \\
\hline Fin Specifications & & & Evaporator wall, $R_{e, \text { wall }}$ & $1.7 \mathrm{E}-3$ & $3.21 \mathrm{E}-4$ \\
\hline Material & Aluminum & Aluminum & Evaporator liquid film, $R_{e, i n}$ & $4.5 \mathrm{E}-3$ & $5.63 \mathrm{E}-4$ \\
\hline Fin diameter (evap./cond.) [m] & N.A./0.275 & $0.265 / 0.265$ & Evaporator interfacial, $R_{e, \text { inter }}$ & $1.18 \mathrm{E}-5$ & $2.43 \mathrm{E}-6$ \\
\hline Thickness (evap./cond.) [mm] & N.A./0.250 & $0.5 / 0.250$ & Axial vapor, $R_{\text {vap }}$ & 7.44E-4 & $9.50 \mathrm{E}-8$ \\
\hline Pitch (evap./cond.) [m] & N.A./0.018 & $0.010 / 0.018$ & Condenser interfacial, $R_{c, \text { inter }}$ & $9.80 \mathrm{E}-7$ & $2.03 \mathrm{E}-7$ \\
\hline Fin efficiency (evap./cond.) & N.A./0.75 & $0.75 / 0.75$ & Condenser liquid film, $R_{c, i n}$ & $2.69 \mathrm{E}-4$ & $2.83 \mathrm{E}-5$ \\
\hline Fin number (evap./cond.) & N.A./334 & $50 / 334$ & Condenser wall, $R_{c, \text { wall }}$ & $1.38 \mathrm{E}-4$ & $2.67 \mathrm{E}-5$ \\
\hline Flow Arrangement & & & Condenser to air, $R_{c, e x}$ & $1.80 \mathrm{E}-3$ & $4.90 \mathrm{E}-3$ \\
\hline $\begin{array}{l}\text { Transverse spacing } \\
\text { (evap./cond.) [m] }\end{array}$ & $0.40 / 0.346$ & $0.40 / 0.346$ & Total internal resistance & $6.70 \mathrm{E}-3$ & $9.39 \mathrm{E}-4$ \\
\hline $\begin{array}{l}\text { Longitudinal spacing } \\
\text { (evap./cond.) [m] }\end{array}$ & $0.346 / 0.40$ & $0.346 / 0.40$ & Total thermal resistance, $R_{T S}$ & $1.22 \mathrm{E}-2$ & $6.40 \mathrm{E}-3$ \\
\hline Unit length [m] & 22.5 & N.A. & Heat Transfer & & \\
\hline Unit width[m] & 5.95 & 5.95 & Total heat transfer $\left[\mathrm{MW}_{\mathrm{th}}\right]$ & 730 & 730 \\
\hline Number of TS along width & 14.88 & 14.88 & Heat rate of one TS $\left(\mathrm{W}_{\mathrm{th}}\right)$ & 1.54E3 & 1.46E3 \\
\hline Elevation of power plant [m] & 0 & 0 & Air temperature rise $\left[{ }^{\circ} \mathrm{C}\right]$ & 4.48 & 12.36 \\
\hline Flow Specifications & & & LMTD (counter-current) $\left[{ }^{\circ} \mathrm{C}\right]$ & 18.67 & 9.31 \\
\hline Hot flow inlet temp $\left[{ }^{\circ} \mathrm{C}\right]$ & 53.0 & 53.0 & Operating pressure of TS, $p_{\text {vap }}[\mathrm{kPa}]$ & 6.56 & 9.40 \\
\hline Hot flow outlet temp $\left[{ }^{\circ} \mathrm{C}\right]$ & 53.0 & 42.0 & System Geometry & & \\
\hline Cold flow inlet temp $\left[{ }^{\circ} \mathrm{C}\right]$ & 32.0 & 32.0 & Unit length [m] & N.A. & 202.55 \\
\hline Hot flow velocity $[\mathrm{m} / \mathrm{s}]$ & N.A. & 0.0921 & Total number of TSs & $4.733 \mathrm{E} 5$ & $5.02 \mathrm{E} 5$ \\
\hline Hot mass flow rate $[\mathrm{kg} / \mathrm{s}]$ & 303.91 & 1.580E4 & Number of units & 490 & 58.0 \\
\hline Cold mass flow rate/unit [kg/s] & 650 & 1500 & Power & & \\
\hline Hot flow quality & 1.0 & 0 & Total cold fan power $\left[\mathrm{MW}_{\mathrm{e}}\right]$ & 1.928 & 0.191 \\
\hline \multicolumn{2}{|c|}{ Thermosyphon Operating Conditions } & & Total pump power $\left[\mathrm{MW}_{\mathrm{e}}\right]$ & N.A. & 3.33 \\
\hline Working fluid & Water & Water & $\begin{array}{l}\text { Total parasitic power (fan + pump } \\
\text { power) }\left[\mathrm{MW}_{\mathrm{e}}\right]\end{array}$ & 1.93 & 3.52 \\
\hline \multicolumn{4}{|l|}{ Performance Indicators } & DDTSC & IDTCT \\
\hline \multicolumn{4}{|l|}{ Total cost [M\$] } & 22.62 & 39.08 \\
\hline \multicolumn{4}{|l|}{ Cost $\left[\$ / \mathrm{kW}_{\mathrm{th}}\right]$} & 30.99 & 53.54 \\
\hline \multicolumn{4}{|l|}{ Coefficient of performance } & 376.20 & 205.87 \\
\hline \multicolumn{4}{|l|}{ Effectiveness } & 0.5492 & 0.7670 \\
\hline
\end{tabular}


Table 3: Hybrid concepts (HPDC, HSCT, HPCT) physical description, thermal characteristics, and performance.

\begin{tabular}{|c|c|c|c|c|c|c|c|}
\hline \multicolumn{4}{|c|}{ Inputs } & \multicolumn{4}{|c|}{ Outputs } \\
\hline System Parameters & HPDC & HSCT & HPCT & Flow Dynamics & HPDC & HSCT & HPCT \\
\hline Cooling load $\left[\mathrm{MW}_{\mathrm{th}}\right]$ & 730 & 730 & 730 & Hot flow velocity $[\mathrm{m} / \mathrm{s}]$ & 3.72 & N.A. & N.A. \\
\hline Pump efficiency & 0.9 & 0.9 & 0.9 & Cold flow velocity $[\mathrm{m} / \mathrm{s}]$ & 4.82 & 1.24 & 1.24 \\
\hline Fan efficiency & 0.9 & 0.9 & 0.9 & $\Delta$ Pair $[\mathrm{Pa}]$ & 5.45 & 2.02 & 2.02 \\
\hline Unit length $[\mathrm{m}]$ & 22.5 & N.A. & N.A. & $\Delta \mathrm{Pe}, \mathrm{ex}[\mathrm{kPa}]$ & N.A. & 186.64 & 186.64 \\
\hline Unit width $[\mathrm{m}]$ & 5.95 & 5.95 & 5.95 & \multicolumn{2}{|l|}{ Heat Transfer Coefficients $\left[\mathrm{W} / \mathrm{m}^{2} \mathrm{~K}\right]$} & & \\
\hline Number of TS along width & 14.88 & 14.88 & 14.88 & Internal liquid film (evap./cond.) & $\begin{array}{l}6.08 \mathrm{E} 3 / \\
8.56 \mathrm{E} 3 \\
\end{array}$ & $\begin{array}{l}9.80 \mathrm{E} 3 / \\
1.52 \mathrm{E} 4 \\
\end{array}$ & $\begin{aligned} 9.80 \mathrm{E} 3 / \\
1.52 \mathrm{E} 4 \\
\end{aligned}$ \\
\hline Heat transfer DDTSC [MW $\left.\mathrm{MW}_{\mathrm{th}}\right]$ & 365 & N.A. & N.A. & External flow to TS (evap./cond.) & $\begin{array}{c}6.97 E 3 / \\
18.12 \\
\end{array}$ & $\begin{array}{c}517.33 / \\
8.54 \\
\end{array}$ & $\begin{array}{c}517.33 / \\
8.54\end{array}$ \\
\hline Heat transfer IDTCT $\left[\mathrm{MW}_{\text {th }}\right]$ & N.A. & 365 & 365 & Thermal Resistance $\left[{ }^{\circ} \mathrm{C} / \mathrm{W}\right]$ & & & \\
\hline $\begin{array}{l}\text { Heat transfer conventional/ } \\
\text { exisiting }\left[\mathrm{MW}_{\text {th }}\right]\end{array}$ & 365 & 365 & 365 & Evaporator to hot flow, $R_{e, e x}$ & $3.70 E-3$ & $5.65 \mathrm{E}-4$ & $5.65 \mathrm{E}-4$ \\
\hline Thermosyphon Specificiations & & & & Evaporator wall, $R_{e, \text { wall }}$ & $1.70 \mathrm{E}-3$ & $3.21 \mathrm{E}-4$ & $3.21 \mathrm{E}-4$ \\
\hline Wallmaterial & S.S. AISI- & S.S. AISI- & S.S. AISI- & Evaporator liquid film, $R_{e, i n}$ & $4.50 \mathrm{E}-3$ & $5.28 \mathrm{E}-4$ & $5.28 \mathrm{E}-4$ \\
\hline wail materıal & 304 & 304 & 304 & Evaporator interfacial, $R_{e, \text { inter }}$ & $1.18 \mathrm{E}-5$ & $2.43 \mathrm{E}-6$ & $2.43 \mathrm{E}-6$ \\
\hline Outer diameter $[\mathrm{m}]$ & 0.025 & 0.125 & 0.125 & Axial vapor, $R_{\text {vap }}$ & $7.44 \mathrm{E}-4$ & $9.50 \mathrm{E}-8$ & $9.50 \mathrm{E}-8$ \\
\hline Inner diameter $[\mathrm{m}]$ & 0.023 & 0.123 & 0.123 & Condenser interfacial, $R_{c, \text { inter }}$ & $9.80 \mathrm{E}-7$ & $2.03 \mathrm{E}-7$ & $2.03 E-7$ \\
\hline Length (evap./cond.) [m] & $0.50 / 6.0$ & $0.50 / 6.0$ & $0.50 / 6.0$ & Condenser liquid film, $R_{c, i n}$ & $2.69 \mathrm{E}-4$ & $2.83 \mathrm{E}-5$ & $2.83 \mathrm{E}-5$ \\
\hline Adiabatic length & 0 & 0 & 0 & Condenser wall, $R_{c, \text { wall }}$ & $1.38 \mathrm{E}-4$ & $2.67 \mathrm{E}-5$ & $2.67 E-5$ \\
\hline Fin Specifications & & & & Condenser to air, $R_{c, e x}$ & $1.80 \mathrm{E}-3$ & $4.90 \mathrm{E}-3$ & $4.90 \mathrm{E}-3$ \\
\hline Material & Aluminum & Aluminum & Aluminum & Total internal resistance & $6.70 \mathrm{E}-3$ & $9.04 \mathrm{E}-4$ & $9.04 \mathrm{E}-4$ \\
\hline Fin diameter (evap./cond.) [m] & N.A./0.275 & $0.265 / 0.265$ & $0.265 / 0.265$ & Total thermal resistance, $R_{T S}$ & $1.22 \mathrm{E}-2$ & $6.40 \mathrm{E}-3$ & $6.40 \mathrm{E}-3$ \\
\hline Thickness (evap./cond.) [mm] & N.A./0.250 & $0.5 / 0.250$ & $0.5 / 0.250$ & Heat Transfer & & & \\
\hline Pitch (evap./cond.) [m] & N.A./0.018 & $0.010 / 0.018$ & $0.010 / 0.018$ & Total heat transfer $\left[\mathrm{MW}_{\mathrm{th}}\right]$ & 730 & 730 & 730 \\
\hline Fin efficiency (evap./cond.) & N.A./0.75 & $0.75 / 0.75$ & $0.75 / 0.75$ & Heat rate of one TS $\left(\mathrm{W}_{\mathrm{th}}\right)$ & $1.54 \mathrm{E} 3$ & $1.47 \mathrm{E} 3$ & 1.47E3 \\
\hline Fin number (evap./cond.) & N.A./334 & $50 / 334$ & $50 / 334$ & Air temperature rise $\left[{ }^{\circ} \mathrm{C}\right]$ & 4.48 & 12.38 & 12.38 \\
\hline Flow Specifications & & & & LMTD (counter-current) $\left[{ }^{\circ} \mathrm{C}\right]$ & 18.67 & 9.30 & 9.30 \\
\hline Hot flow inlet temp $\left[{ }^{\circ} \mathrm{C}\right]$ & 53 & 53 & 53 & Operating pressure TS, $p_{\text {vap }}[\mathrm{kPa}]$ & 6.56 & 9.42 & 9.42 \\
\hline Hot flow outlet temp $\left[{ }^{\circ} \mathrm{C}\right]$ & 53 & 42 & 42 & System Geometry & & & \\
\hline Air flow inlet temp $\left[{ }^{\circ} \mathrm{C}\right]$ & 32 & 32 & 32 & Unit length $[\mathrm{m}]$ & N.A. & 200.9 & 200.9 \\
\hline Hot flow velocity per unit $[\mathrm{m} / \mathrm{s}]$ & N.A. & 0.0921 & 0.0921 & Total number of TSs & $2.36 \mathrm{E} 5$ & $2.49 \mathrm{EE} 5$ & $2.49 \mathrm{E} 5$ \\
\hline Rankine mass flow rate $[\mathrm{kg} / \mathrm{s}]$ & 303.91 & 303.91 & 303.91 & Number of units & 245 & 29 & 29 \\
\hline Cold mass flow rate/unit $[\mathrm{kg} / \mathrm{s}]$ & 650 & 1500 & 1500 & Power & & & \\
\hline Hot flow quality & 1 & 0 & 0 & Total cold fan power $\left[\mathrm{MW}_{\mathrm{e}}\right]$ & 0.964 & 0.097 & 0.097 \\
\hline Recirculation mass flow rate & $7.90 \mathrm{E} 3$ & $7.90 \mathrm{E} 3$ & $1.58 \mathrm{E} 4$ & Pump power $\left[\mathrm{MW}_{\mathrm{e}}\right]$ & N.A. & 1.638 & 1.638 \\
\hline $\begin{array}{l}\text { Temperature leaving } \\
\text { conventional condenser }\left[{ }^{\circ} \mathrm{C}\right]\end{array}$ & 47.5 & 53 & 53 & Recirculation pump power $\left[\mathrm{MW}_{\mathrm{e}}\right]$ & 0.754 & 0.754 & 1.595 \\
\hline $\begin{array}{l}\text { Temperature leaving } \\
\text { conventional cooling tower }\left[{ }^{\circ} \mathrm{C}\right]\end{array}$ & 25 & 25 & 36 & $\begin{array}{l}\text { Total parasitic power (fan + pump } \\
\text { power)[MW }]\end{array}$ & 1.718 & 2.489 & 3.330 \\
\hline Performance Indicators & & & & & HPDC & HSCT & HPCT \\
\hline Water loss $[\mathrm{kg} / \mathrm{s}]$ & & & & & 157.50 & 157.50 & 157.50 \\
\hline Dry cooling estimated cost [M\$] & & & & & 11.31 & 19.38 & 19.38 \\
\hline Estimated existing cost [M\$̦] & & & & & 5.13 & 5.13 & 5.13 \\
\hline Total cost [M\$] & & & & & 16.44 & 24.51 & 24.51 \\
\hline $\operatorname{Cost}\left[\$ / \mathrm{kW}_{\mathrm{th}}\right]$ & & & & & 22.52 & 33.58 & 33.58 \\
\hline Coefficient of performance & & & & & 423.55 & 292.25 & 218.45 \\
\hline Effectiveness & & & & & 0.71 & 0.53 & 0.53 \\
\hline
\end{tabular}


Table 4: Cooling Efficiency and Estimated Payback Period Compared to Wet Cooling

\begin{tabular}{|l|c|c|c|}
\hline & Wet Cooled Plant & DDTSC & IDTSC \\
\hline Cooling efficiency $^{\mathrm{a}}$ & $66.00 \%$ & $41.43 \%$ & $34.49 \%$ \\
\hline${\text { Water use }(\mathrm{M} \mathrm{G} / \mathrm{yr})^{\mathrm{b}}}$ & 822.77 & 0 & 0 \\
\hline${\text { Cost of water consumption }[\mathrm{M} \$ / \mathrm{yr}]^{\mathrm{c}}}^{\mathrm{c}}$ & 5.52 & 0 & 0 \\
\hline Estimated cost of materials $[\mathrm{M} \$]^{\mathrm{a}}$ & 22.50 & 22.62 & 39.08 \\
\hline Cost factor & N.A. & 2 & 2 \\
\hline Total system cost $[\mathrm{M} \$]$ & 22.50 & 45.24 & 78.16 \\
\hline Time until payback $[\mathrm{yrs}]$ & N.A. & 8.19 & 14.16 \\
\hline
\end{tabular}

a Based on values outlined by Tsou et al. (2013)

${ }^{b}$ Average water consumption is based on values given by Maulbetsch and DiFilippo (2006)

c The annual cost of water is calculated using $\$ 5.02 / \mathrm{HCF}$, representative of the cost of water in San Diego, California (City of San Diego Public Utilities Department, 2016) 